\title{
$\beta$ relaxation and low-temperature aging in a Au-based bulk metallic glass: From elastic properties to atomic-scale structure
}

\author{
Z. Evenson, ${ }^{1,2, *}$ S. E. Naleway,${ }^{3}$ S. Wei, ${ }^{1}$ O. Gross, ${ }^{1}$ J. J. Kruzic, ${ }^{3}$ I. Gallino, ${ }^{1}$ W. Possart, ${ }^{4}$ M. Stommel, ${ }^{5}$ and R. Busch ${ }^{1}$ \\ ${ }^{1}$ Chair for Metallic Materials, Saarland University, Campus C6.3, D-66123 Saarbrücken, Germany \\ ${ }^{2}$ Institut für Materialphysik im Weltraum, Deutsches Zentrum für Luft- und Raumfahrt (DLR), 51147 Köln, Germany \\ ${ }^{3}$ Material Science, School of Mechanical, Industrial, and Manufacturing Engineering, Oregon State University, Corvallis, Oregon 97331, USA \\ ${ }^{4}$ Chair for Adhesion and Interphases in Polymers, Saarland University, Campus C6.3, D-66123 Saarbrücken, Germany \\ ${ }^{5}$ Chair for Polymer Materials, Saarland University, Campus C6.3, D-66123 Saarbrücken, Germany
}

(Received 16 March 2014; published 29 May 2014)

\begin{abstract}
The slow $\beta$ relaxation is understood to be a universal feature of glassy dynamics. Its presence in bulk metallic glasses (BMGs) is evidence of a broad relaxation time spectrum that extends to deep within the glassy state. Despite the breadth of research devoted to this phenomenon, its microscopic origin is still not fully understood. The low-temperature aging behavior and atomic structural rearrangements of $\mathrm{Au}_{49} \mathrm{Cu}_{26.9} \mathrm{Si}_{16.3} \mathrm{Ag}_{5.5} \mathrm{Pd}_{2.3} \mathrm{BMG}$ are investigated in the regime of the slow $\beta$ relaxation by employing an ensemble of experimental techniques such as high-intensity synchrotron x-ray scattering, modulated differential scanning calorimetry (MDSC), dynamic mechanical analysis (DMA), impulse excitation, and dilatometry. Evidence of a distinct slow $\beta$-relaxation regime is seen in the form of (1) an excess wing of the DMA loss modulus beginning at $\sim 50{ }^{\circ} \mathrm{C}$, (2) a crossover effect of elastic modulus with isothermal aging at $50^{\circ} \mathrm{C}$, and (3) a broad, nonreversing and largely irreversible sub- $T_{g}$ endotherm in the MDSC results. Atomic rearrangements occurring at the onset of the measured slow $\beta$-relaxation temperature regime were found to be confined mainly to the short-range order length scale while no significant atomic rearrangements occur on the length scale of the medium-range order. Furthermore, evidence is presented that suggests the crossover effect in Young's modulus is due to the evolution of chemical short-range order. These results support the emergent picture of a dynamically heterogeneous glassy structure, in which low-temperature relaxation occurs through atomic rearrangements confined mostly to the short-range order length scale.
\end{abstract}

DOI: 10.1103/PhysRevB.89.174204

PACS number(s): 64.70.pe, 61.20.Lc, 81.40.Jj, 81.70.Pg

\section{INTRODUCTION}

The stability of bulk metallic glass (BMG) properties over time is essential to their achieving successful use in commercial applications such as transportation, energy, and consumer products. Due to their amorphous nature, temperature can affect BMGs in ways not experienced by crystalline metals. For example, the process called structural relaxation (or $\alpha$ relaxation) will occur at relatively short-time scales (e.g., minutes or hours) during isothermal aging at temperatures $\sim 90 \%$ to $95 \%$ of the caloric glass transition temperature $T_{g}$ [1-4]. Aging near $T_{g}$ can be observed as a densification of the glass and can cause profound effects on the elastic [5], deformation, and fracture [5-8], as well as fatigue properties of BMGs [8,9]. Thus, it is important that the experienced temperatures for applications avoid measurable $\alpha$ relaxation during the service life to ensure stable mechanical performance. In addition to the $\alpha$ relaxation, metallic glasses have been shown to exhibit aging behavior at temperatures far below $T_{g}$. For example, studies on thin metallic glass ribbons have observed physical properties such as elastic modulus or Curie temperature to evolve with annealing at temperatures where $\alpha$-relaxation times would be too long to expect noticeable changes [10-15]. These relaxations have been separated into rearrangements in chemical short-range order (CSRO), a reversible phenomenon related to the chemical surroundings of atoms, and changes in topological short-range order (TSRO), an irreversible phenomenon related to changes in interatomic

*Zachary.Evenson@dlr.de distances and a densification of the glass. Moreover, by first preannealing at low temperatures, a crossover minimum can be observed in property trends upon annealing at a higher temperature [10-15]. This crossover effect has been attributed to (1) the reversible nature of the CSRO changes and (2) the different relaxation times associated with CSRO and TSRO.

More recently, there have been many reports of observations of a slow $\beta$ (or Johari-Goldstein [16]) relaxation ${ }^{1}$ in BMGs commonly characterized by a peak in the loss modulus versus temperature curve measured using dynamic mechanical analysis (DMA) at a constant heating rate [17-24]. The observed peak temperature depends on the test frequency, increasing at higher frequencies, and hence the peak can often overlap with the dynamic $\alpha$-relaxation peak, appearing as an excess wing or inflection, and may approach the dynamic $T_{g}$ at $\mathrm{MHz}$ frequencies [17-24]. By considering a heterogeneous model of BMG atomic structure with both higher free volume soft regions and denser hard regions, it has been suggested that atomic rearrangements during the slow $\beta$ relaxation occur in the soft, higher free volume regions $[25,26]$. Furthermore, it has been reported that the topological rearrangements are closely related to those that occur in shear transformation zones (STZs) during deformation, and a one-to-one correlation has been reported between the activation energy for the slow $\beta$ relaxation and the potential energy barrier for unsheared STZs [18].

\footnotetext{
${ }^{1}$ This is not to be confused with the fast $\beta$ relaxation, which occurs at high temperatures in the melt on time scales of typically $10^{-13}$ $10^{-9} \mathrm{~s}$
} 
Despite the importance of the topic, there is still much unknown about the process of the slow $\beta$ relaxation in BMGs. Accordingly, the purpose of this paper is to use modulated differential scanning calorimetry (MDSC) and high-intensity synchrotron x-ray scattering results in concert with more conventional experiments (e.g., DSC, DMA, dilatometry, and impulse excitation) to present a more comprehensive understanding of the mechanisms associated with the slow $\beta$ relaxation in BMGs.

\section{EXPERIMENT}

BMG samples with the nominal composition $\mathrm{Au}_{49} \mathrm{Cu}_{26.9} \mathrm{Si}_{16.3} \mathrm{Ag}_{5.5} \mathrm{Pd}_{2.3}$ were used in this study [27]. Common applications of crystalline Au-based alloys include dentistry and jewelry where the application temperature is near $37^{\circ} \mathrm{C}$. This specific BMG was chosen for this study because its target application temperature lies in the potential range of the slow $\beta$ relaxation; however, it is expected that the results of this study should be relevant to understanding relaxation processes of BMGs in general. BMG samples were produced by inductively melting the pure elements (purity $>99.995 \%$ ) in an $\mathrm{Al}_{2} \mathrm{O}_{3}$ crucible inside of an Indutherm MC15 tilt-casting device under vacuum at pressures $<10^{-3}$ mbar and then tilt-casting in a high-purity argon-flushed atmosphere into a water-cooled $\mathrm{Cu}$ mold. To prevent room-temperature aging of the material, all samples were stored in a freezer at roughly $-18^{\circ} \mathrm{C}$ and the time spent out of the freezer for machining or experiments was minimized to the greatest extent possible. All samples were shown to be amorphous by x-ray diffraction prior to all experiments.

DMA was used to determine the dynamic $\beta$-relaxation temperature for the nominal $\mathrm{Au}_{49} \mathrm{Cu}_{26.9} \mathrm{Si}_{16.3} \mathrm{Ag}_{5.5} \mathrm{Pd}_{2.3} \mathrm{BMG}$ composition. The DMA experiments were performed using a TA DMA-Q800 at a constant heating rate of $0.05 \mathrm{~K} / \mathrm{s}$. Modulus calibration was carried out using $\mathrm{Al}$ samples and the data were collected in three-point bending with a 30-mm support span using rectangular plate samples with approximate cross sections of $2 \times 10 \mathrm{~mm}^{2}$ and a length of $33 \mathrm{~mm}$. Tests were conducted at loading frequencies of $v=0.1,1$, and $10 \mathrm{~Hz}$, at a bending amplitude of $20 \mu \mathrm{m}$. The tests were begun at a temperature of $0{ }^{\circ} \mathrm{C}$ and terminated at $165^{\circ} \mathrm{C}$ or when the sample plastically deformed, whichever came first.

Room-temperature measurements of the Young's modulus were taken as a function of isothermal aging time using the impulse excitation of vibration method described in ASTM E1876 [28]. Two samples of $\mathrm{Au}_{49} \mathrm{Cu}_{26.9} \mathrm{Si}_{16.3} \mathrm{Ag}_{5.5} \mathrm{Pd}_{2.3}$ were tested using this method. The samples had a nominal thickness of $2.5 \mathrm{~mm}$, length of $31 \mathrm{~mm}$, and widths ranging from 9-12.5 mm. Measurements were made as a function of isothermal anneal time at temperatures of $50{ }^{\circ} \mathrm{C}$ and $37^{\circ} \mathrm{C}$. The former temperature was chosen near the onset of the dynamic $\beta$-relaxation peak in the DMA and the latter near the expected service temperature of the material, while both temperatures are sufficiently low so that $\alpha$ relaxation would be assumed to be negligible during the experimental time scales. Anneal temperatures and treatments were achieved using a temperature-controlled $( \pm 0.1 \mathrm{~K})$ deionized water bath. Samples were placed into the water bath to anneal and were then removed and brought to room temperature by placing in a $20{ }^{\circ} \mathrm{C}$ water bath for $\sim 30$ s. Samples were then dried and tested in air at room temperature as prescribed in ASTM E1876 before resuming the isothermal aging process.

DSC measurements were carried out in a powercompensated Perkin Elmer HyperDSC 8500, calibrated according to the melting transitions of water, In and Sn. MDSC measurements were carried out in a TA DSC-Q100 calibrated according to the melting temperatures of In and Sn. The MDSC measurements employed an underlying constant part of the heating/cooling rate of $\pm 0.083 \mathrm{~K} / \mathrm{s}$, modulation amplitude of $1 \mathrm{~K}$, and period of $60 \mathrm{~s}$. During the first heating cycle, an as-cast sample was heated to a temperature of $150^{\circ} \mathrm{C}$ into the supercooled liquid region, then cooled with the same rate down to $-25^{\circ} \mathrm{C}$. During the second heating cycle, the sample was reheated from $-25^{\circ} \mathrm{C}$ past the glass transition and through the supercooled liquid region. Additionally, a Netzsch TMA-402, calibrated according to the melting standards of hexatriacontane, In and $\mathrm{Zn}$, was used to measure the thermal expansion of an as-cast sample of $\mathrm{Au}_{49} \mathrm{Cu}_{26.9} \mathrm{Si}_{16.3} \mathrm{Ag}_{5.5} \mathrm{Pd}_{2.3}$ at temperatures starting from $23{ }^{\circ} \mathrm{C}$ in a high-purity $\mathrm{Ar}$ atmosphere at a heating rate of $0.083 \mathrm{~K} / \mathrm{s}$.

Synchrotron $\mathrm{X}$-ray scattering experiments were carried out using the PETRA III high-intensity beamline P02.1 at HASYLAB/DESY in Hamburg. Samples were prepared for the synchrotron experiments by cutting $\sim 200-\mu \mathrm{m}$-thick disks from 5-mm-diameter cast rods. The x-ray experiments were carried out in transmission mode using a Perkin Elmer XRD1621 CsI bonded amorphous silicon detector (2048 pixels $\times$ 2048 pixels, $200 \mu \mathrm{m}^{2}$ pixel size). The beam size was 0.8 $\times 0.8 \mathrm{~mm}^{2}$ with a wavelength of $0.207 \AA(59.83 \mathrm{keV})$. The temperature profile was applied under a constant flow of high-purity Ar inside of a Linkam THMS 600 furnace. Prior to each measurement, the samples were first cooled to $0{ }^{\circ} \mathrm{C}$ using a steady stream of liquid nitrogen vapor. A thermal cycling furnace run was performed, in which the sample was heated from the glassy state at $0{ }^{\circ} \mathrm{C}$ with a rate of $q_{H}=0.33 \mathrm{~K} / \mathrm{s}$ to $145^{\circ} \mathrm{C}$, into the supercooled liquid. The sample was then cooled back down to $0^{\circ} \mathrm{C}$ with a cooling rate $q_{C}=0.33 \mathrm{~K} / \mathrm{s}$ and subsequently reheated with the same rate to a temperature of $250^{\circ} \mathrm{C}$, well past the beginning of crystallization at $\sim 175^{\circ} \mathrm{C}$. X-ray measurements were performed at 6-s intervals during heating and cooling, yielding a total of 300 spectra. Additionally, an isothermal furnace run was performed on a separate as-cast sample, in which the sample was heated from $0{ }^{\circ} \mathrm{C}$ to $50{ }^{\circ} \mathrm{C}$ at a rate of $0.33 \mathrm{~K} / \mathrm{s}$ and held there for a period of $7800 \mathrm{~s}(\sim 2 \mathrm{~h})$. During this time, $\mathrm{x}$-ray spectra were collected in 12-s intervals, resulting in a total of 650 spectra. The integrated intensities $I(Q)$ were obtained from the two-dimensional raw diffraction data using the FIT2D data analysis software [29]. After furnace background subtraction, the total structure factor $S(Q)$ was obtained from the raw $I(Q)$ data using PDFGETX3 [30].

\section{RESULTS}

\section{A. Dynamic mechanical analysis (DMA)}

Values of the loss modulus for each test frequency normalized to the loss modulus at $0{ }^{\circ} \mathrm{C}, E^{\prime \prime} / E_{0}^{\prime \prime}$, are shown as a function of temperature in Fig. 1. The low-temperature 


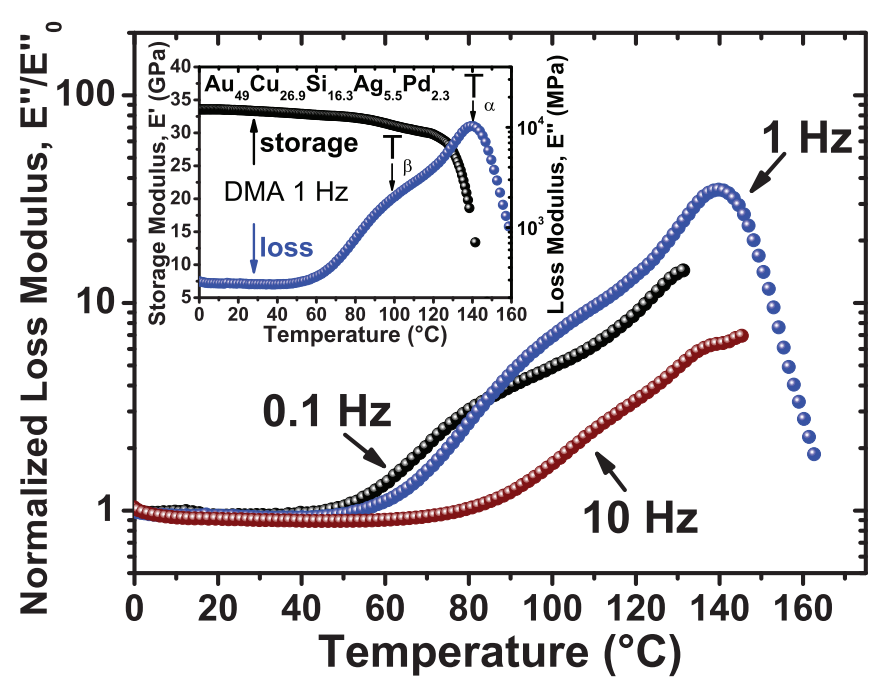

FIG. 1. (Color online) Normalized loss modulus determined at different frequencies by DMA for $\mathrm{Au}_{49} \mathrm{Cu}_{26.9} \mathrm{Si}_{16.3} \mathrm{Ag}_{5.5} \mathrm{Pd}_{2.3}$ using a heating rate of $0.05 \mathrm{~K} / \mathrm{s}$. The inset shows the values of $E^{\prime}$ and $E^{\prime \prime}$ as a function of temperature for a test frequency of $v=1 \mathrm{~Hz}$.

loss moduli used for normalization were 528, 277, and $929 \mathrm{MPa}$ for test frequencies of $0.1,1$, and $10 \mathrm{~Hz}$, respectively. The normalized loss modulus curves in Fig. 1 display an excess wing on the $\alpha$-relaxation peak, appearing around $50^{\circ} \mathrm{C}$. Furthermore, a shoulder, or hump, appears on the low-temperature end of the $\alpha$-relaxation peak. This shoulder is identified as the dynamic $\beta$-relaxation peak and tends to shift to higher temperatures at higher test frequencies. In the inset of Fig. 1, the values of $E^{\prime}$ and $E^{\prime \prime}$ are shown as a function of temperature for $v=1 \mathrm{~Hz}$. For this test frequency at the heating rate of $0.05 \mathrm{~K} / \mathrm{s}$, the temperature of the dynamic $\alpha$-relaxation peak $T_{\alpha}$ was determined to be $139.8^{\circ} \mathrm{C}$. Furthermore, the peak in the excess wing indicative of the dynamic $\beta$ relaxation occurred for $v=1 \mathrm{~Hz}$ at $T_{\beta}=91.7^{\circ} \mathrm{C}$.

\section{B. Impulse excitation}

While DMA measures change in dynamic elastic properties over relatively short-time scales, it is also of interest to understand the evolution of properties over long-time scales due to isothermal annealing. Since the elastic properties are a function of the test temperature, preliminary tests were conducted to establish the procedure for cooling and equilibrating the temperature before each measurement. Samples were allowed to slowly reach room temperature $\left(20^{\circ} \mathrm{C}\right)$, then quickly quenched in an ice bath $\left(0^{\circ} \mathrm{C}\right)$ for varying time periods, and then tested at the lower temperature. These tests showed that after $3 \mathrm{~s}$ of temperature equilibration time in the ice bath, no further changes in the elastic properties were observed. Thus, the $\sim 30$-s hold time used was considered more than sufficient to equilibrate the sample at room temperature.

Measurements of the Young's modulus normalized to the initial Young's modulus $E / E_{0}$ (taken before testing at room temperature in the as-cast state) are shown as a function of annealing time in a deionized water bath in Fig. 2. Due to the high precision of the test method, often repeated

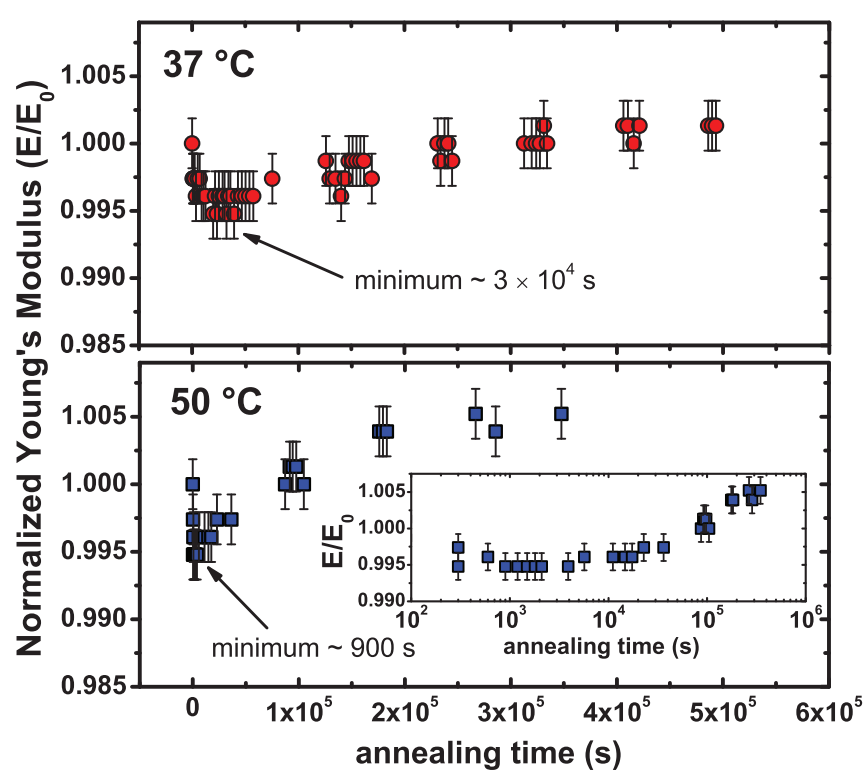

FIG. 2. (Color online) Normalized Young's modulus $E / E_{0}$ as a function of annealing time for samples annealed at $37^{\circ} \mathrm{C}$ and (top, red circles) and $50{ }^{\circ} \mathrm{C}$ (bottom, blue squares). For better clarity, the data corresponding to an annealing temperature of $50{ }^{\circ} \mathrm{C}$ are also shown on a logarithmic time scale (inset, bottom).

measurements yielded identical results with no apparent standard deviation. The error bars shown in Fig. 2 were the worst case standard deviation that was observed and it was established by extensively testing each sample in the as-cast state prior to annealing. Such extensive data collection for each annealing time was not performed in order to limit the time spent outside the annealing bath. While isothermal aging to induce $\alpha$-structural relaxation is reported to decrease the Poisson's ratio of BMGs [5], no variation in the Poisson's ratio [e.g., $\left.v\left(50^{\circ} \mathrm{C}\right)=0.431 \pm 0.001\right]$ was observed in this study. However, $E / E_{0}$ was observed to evolve over time at both $37^{\circ} \mathrm{C}$ and $50^{\circ} \mathrm{C}$; these data are shown in Fig. 2 as red circles and blue squares, respectively. At both temperatures, a crossover effect is observed with an initial quick drop in modulus followed by a slower rise in modulus after the minimum value is reached. At $37^{\circ} \mathrm{C}$, the minimum in modulus that marks the transition between the initial quick drop and slower rise occurs after a longer anneal than at $50^{\circ} \mathrm{C}$. The trough minimum is located at a time of $\sim 30000 \mathrm{~s}$ for $37^{\circ} \mathrm{C}$ compared to a time of $\sim 900 \mathrm{~s}$ for $50^{\circ} \mathrm{C}$.

\section{Differential scanning calorimetry (DSC/MDSC)}

To further understand the changes in this BMG in the temperature range of the dynamic $\beta$ relaxation, both conventional DSC and MDSC experiments were performed. Caloric $T_{g}$ values for BMGs depend on the heating rate used for the measurement and a value of $123^{\circ} \mathrm{C}$ is determined for this BMG composition at a heating rate of $0.33 \mathrm{~K} / \mathrm{s}$ using DSC [curve (a) in Fig. 3]. Figure 3 shows conventional DSC thermograms at a heating rate of $0.33 \mathrm{~K} / \mathrm{s}$ for four different samples of $\mathrm{Au}_{49} \mathrm{Cu}_{26.9} \mathrm{Si}_{16.3} \mathrm{Ag}_{5.5} \mathrm{Pd}_{2.3}$, each corresponding to a different thermal treatment: (a) as-cast rod, (b) $1 \mathrm{~s}$ annealing at $50^{\circ} \mathrm{C}$, 


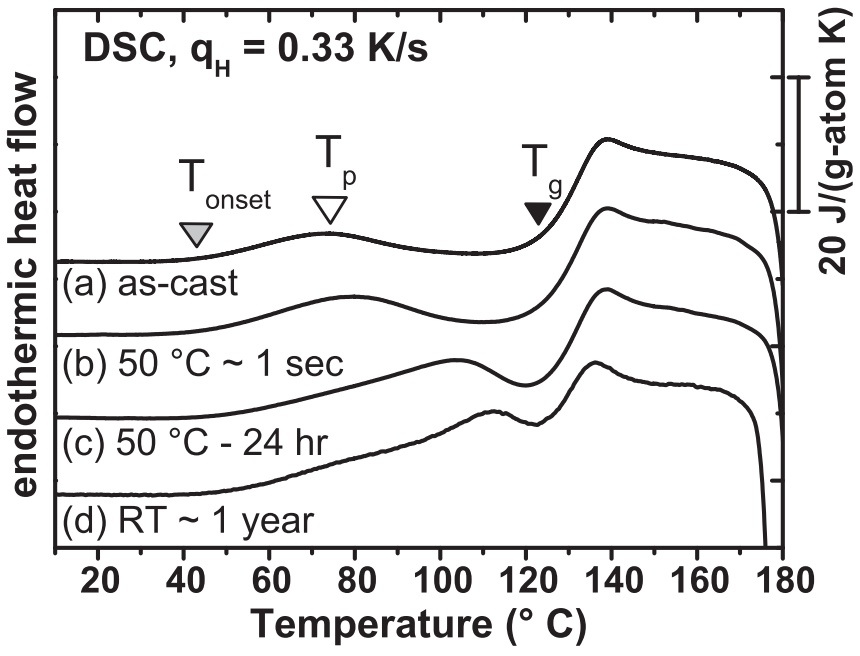

FIG. 3. DSC up scans (endotherms up) at a heating rate of $0.33 \mathrm{~K} / \mathrm{s}$. Each sample was subjected to different thermal treatments: (a) as-cast, (b) annealing at $50^{\circ} \mathrm{C}$ for $\sim 1 \mathrm{~s}$, (c) annealing at $50^{\circ} \mathrm{C}$ for $24 \mathrm{~h}$, and (d) aging at room temperature (RT) for $\sim 1$ year. The curves are vertically translated for better comparison.

(c) $24 \mathrm{~h}$ annealing at $50{ }^{\circ} \mathrm{C}$, and (d) aging for $\sim 1$ year under room conditions. Samples that were never heated above $T_{g}$ exhibited a pronounced sub- $T_{g}$ endotherm in their DSC thermograms, with the location of the endotherm peak shifting to higher temperatures with isothermal aging in the vicinity of the slow $\beta$-relaxation temperature. The onset and peak of the sub- $T_{g}$ endotherm is indicated for the as-cast sample in Fig. 3 as $T_{\text {onset }}=43^{\circ} \mathrm{C}$ and $T_{p}=74^{\circ} \mathrm{C}$, respectively.

In contrast to conventional DSC, MDSC measurements employ a sinusoidal varying temperature profile, superimposed onto a constant underlying heating rate. The temperature profile can be expressed as

$$
T(t)=T_{i}+q_{H} t+A_{T} \sin (\omega t),
$$

where $T_{i}$ is the initial temperature, $q_{H}$ is the underlying heating rate, $A_{T}$ is the amplitude of the temperature oscillations, and $\omega=(2 \pi t) / p$ is the angular frequency with $p$ as the period. Usually, small values of $A_{T}(\sim 1 \mathrm{~K})$ are employed, such that the kinetic response of the system can be considered as linear. For a more comprehensive review of the MDSC method, the reader is referred to Ref. [31].

MDSC experiments were performed in order to separate the total heat flow signal of the $\mathrm{Au}_{49} \mathrm{Cu}_{26.9} \mathrm{Si}_{16.3} \mathrm{Ag}_{5.5} \mathrm{Pd}_{2.3}$ BMG into its thermodynamic (heat capacity) and kinetic components. In Fig. 4(a), the total heat flow signals are shown for the first and second heating cycles. The reversing and nonreversing curves are shown for the first and second heating in Figs. 4(b) and 4(c), respectively. The sub- $T_{g}$ endotherm of the as-cast sample is seen here as a broad endothermic peak appearing in the nonreversing signal and is absent in the reversing signal. This is typical of kinetic processes such as enthalpy recovery. The as-cast sample shows a much greater enthalpy associated with the sub- $T_{g}$ endotherm than the slowly cooled sample [compare shaded areas in Figs. 4(b) and 4(c): 155 and $25 \mathrm{~J} / \mathrm{g}$-atom, respectively]. Additionally,

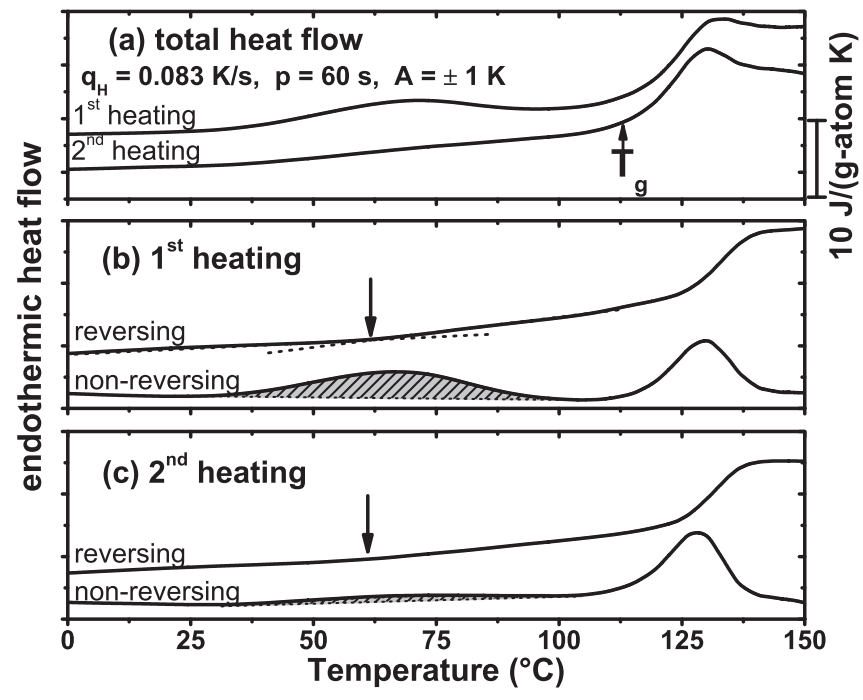

FIG. 4. MDSC thermograms of $\mathrm{Au}_{49} \mathrm{Cu}_{26.9} \mathrm{Si}_{16.3} \mathrm{Ag}_{5.5} \mathrm{Pd}_{2.3}$ showing (a) the total heat flow for the first and second heatings, (b) the separated reversing and nonreversing components for the first heating, and (c) the separated reversing and nonreversing components for the second heating. The shaded area shows the enthalpy associated with the sub- $T_{g}$ endotherm. The black arrows indicate the change in slope at $60^{\circ} \mathrm{C}$ observed in the reversing signals. The curves have been vertically translated for better comparison.

the reversing signal in both heating cycles is marked by a distinct endothermic change in slope appearing at $\sim 60^{\circ} \mathrm{C}$ during heating [dotted lines in Fig. 4(b)].

\section{High-intensity $x$-ray scattering}

The total x-ray structure factor $S(Q)$ can be expressed as

$$
S(Q)=1+\frac{I_{c}(Q)-\left\langle f(Q)^{2}\right\rangle}{\langle f(Q)\rangle^{2}},
$$

where $I_{c}(Q)$ is the coherently scattered intensity, $f(Q)$ is the atomic form factor, and $Q$ is the scattering vector. The angle brackets denote an average over all types of constituent elements, i.e., $\left\langle f(Q)^{2}\right\rangle=\sum X_{i} f_{i}(Q)^{2}$ and $\langle f(Q)\rangle^{2}=$ $\left[\sum X_{i} f_{i}(Q)\right]^{2}$, where $f_{i}(Q)$ is the atomic form factor of element $i$ and $X_{i}$ is the molar concentration. According to the definition in Eq. (2), a realistic form of $S(Q)$ should oscillate around 1 for large- $Q$ values. In an $n$-component system, the total $S(Q)$ comprises a weighted sum of all $n(n+1) / 2$ partial structure factors

$$
S(Q)=\sum_{i \leqslant j} W_{i j}(Q) S_{i j}(Q),
$$

where the weighting factor $W_{i j}(Q)$ in the Faber-Ziman formalism [32] can be expressed as

$$
W_{i j}(Q)=\frac{\left(2-\delta_{i j}\right) X_{i} X_{j} f_{i}(Q) f_{j}(Q)}{\langle f(Q)\rangle^{2}} .
$$

Figure 5 shows the $S(Q)$ of an as-cast sample of the $\mathrm{Au}_{49} \mathrm{Cu}_{26.9} \mathrm{Si}_{16.3} \mathrm{Ag}_{5.5} \mathrm{Pd}_{2.3} \mathrm{BMG}$ determined at a temperature of $0{ }^{\circ} \mathrm{C}$. The $S(Q)$ profile at $0^{\circ} \mathrm{C}$ displays a large diffuse peak located at $Q_{0}=2.826 \AA^{-1}$. At higher scattering vectors, 


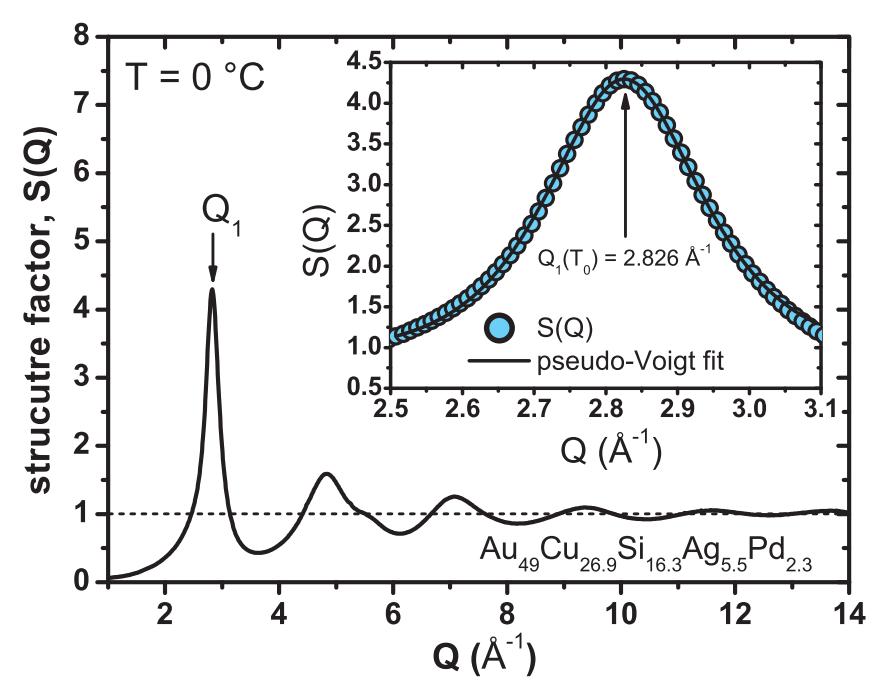

FIG. 5. (Color online) Total structure factor $S(Q)$ of an as-cast sample of $\mathrm{Au}_{49} \mathrm{Cu}_{26.9} \mathrm{Si}_{16.3} \mathrm{Ag}_{5.5} \mathrm{Pd}_{2.3}$ at $T_{0}=0{ }^{\circ} \mathrm{C}$. The first structure factor maximum is located at a scattering vector of $Q_{1}\left(T_{0}\right)=$ $2.826 \AA^{-1}$. The inset shows the pseudo-Voigt function (solid line) used to determine the peak parameters.

broad oscillations appear in the $S(Q)$ and rapidly decay out to scattering vectors of $\sim 14 \AA^{-1}$. These general features are characteristic of amorphous materials in which no long-range order is present. The first structure factor maximum was fitted with a pseudo-Voigt function having the analytical form

$$
f_{P V}(x)=f_{\max }[\eta C(x)+(1-\eta) G(x)],
$$

where $C(x)=\left(1-x^{2}\right)^{-1}$ and $G(x)=\exp \left[-(\ln 2) x^{2}\right]$, with $x=\left(Q-Q_{1}\right) / w$. In this profile, $f_{\max }$ is the amplitude of the peak, $w$ is the full-width at half-maximum (FWHM), $Q_{1}$ is the position of the peak maximum, and $\eta$ is the pseudo-Voigt mixing parameter. The inset of Fig. 5 shows the experimental $S(Q)$ data (cyan circles) corresponding to the first structure factor maximum fitted with the pseudo-Voigt function of Eq. (5) (solid line).

As proposed by Yavari et al. [33], the change in position of $Q_{1}$ during thermal treatment can be related to the change in mean atomic volume through

$$
\left(\frac{Q_{1}\left(T_{0}\right)}{Q_{1}(T)}\right)^{3}=\frac{V(T)}{V\left(T_{0}\right)}=1+\gamma\left(T-T_{0}\right),
$$

where $T_{0}$ is a reference temperature (in this work, $0^{\circ} \mathrm{C}$ ), $\mathrm{V}$ is the mean atomic volume, and $\gamma$ is the volumetric coefficient of thermal expansion. During thermal expansion, the value of $Q_{1}$ decreases with increasing temperature; as such, the relation in Eq. (6) also tracks the change in macroscopic volume. This relation has been successfully applied to quantify free volume changes during structural relaxation of a $\mathrm{Pd}_{40} \mathrm{Cu}_{30} \mathrm{Ni}_{10} \mathrm{P}_{20}$ BMG [33], as well as to measure strain during in situ compression tests of a $\mathrm{Zr}_{57} \mathrm{Ti}_{5} \mathrm{Cu}_{20} \mathrm{Ni}_{8} \mathrm{Al}_{10}$ BMG [34]. Most recently, it has been employed in identifying a liquid-liquid transition in the undercooled melt of the $\mathrm{Zr}_{41.25} \mathrm{Ti}_{13.75} \mathrm{Ni}_{10} \mathrm{Cu}_{12.5} \mathrm{Be}_{22.5}$ BMG-forming liquid [35].

Figure 6 shows the evolution of $\left[Q_{1}\left(T_{0}\right) / Q_{1}(T)\right]^{3}$ with temperature during thermal cycling $\left(q_{H}=q_{C}=0.33 \mathrm{~K} / \mathrm{s}\right)$

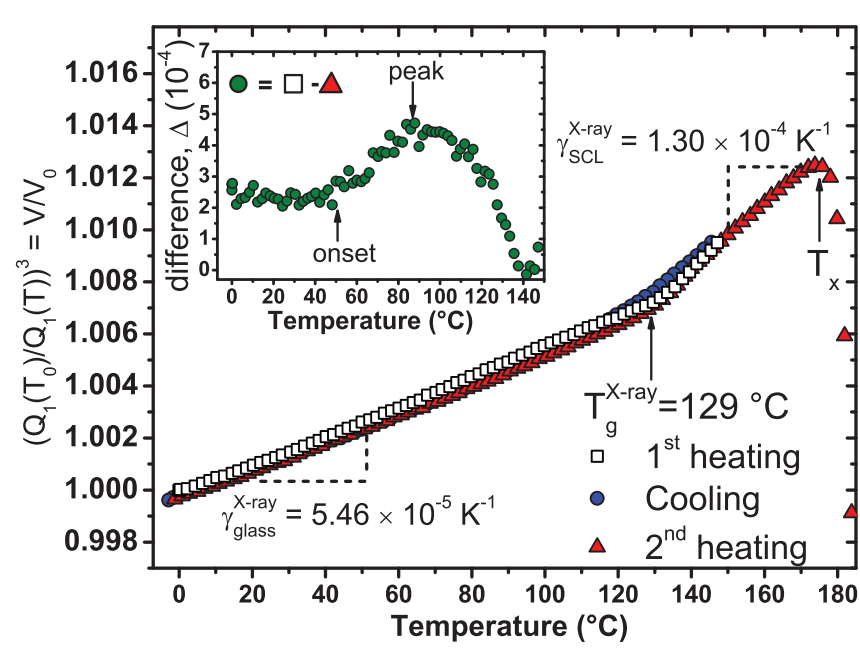

FIG. 6. (Color online) Relative atomic volume changes $\left[Q_{1}\left(T_{0}\right) / Q_{1}(T)\right]^{3}=V / V_{0}$ during thermal cycling: first heating from $0^{\circ} \mathrm{C}$ to $145^{\circ} \mathrm{C}$ (open squares), subsequent cooling from $145^{\circ} \mathrm{C}$ to $0{ }^{\circ} \mathrm{C}$ (blue circles), and second heating from $0{ }^{\circ} \mathrm{C}$ to $250^{\circ} \mathrm{C}$ (red triangles). The inset shows the difference $\Delta$ (green circles) between first and second heating runs.

of a sample of $\mathrm{Au}_{49} \mathrm{Cu}_{26.9} \mathrm{Si}_{16.3} \mathrm{Ag}_{5.5} \mathrm{Pd}_{2.3}$ beginning from its initial as-cast state at $T_{0}=0{ }^{\circ} \mathrm{C}$. The data corresponding to the first heating (empty squares) up to $145^{\circ} \mathrm{C}$ are shown alongside those from the subsequent cooling (blue circles) and second heating (red triangles) runs. The appearance of a distinct change in slope of the experimental data for both heating runs signifies the onset of the caloric glass transition, recorded here as $T_{g}^{\mathrm{x} \text {-ray }}=129^{\circ} \mathrm{C}$. The beginning of crystallization is denoted by $T_{x} \sim 175^{\circ} \mathrm{C}$, the temperature at which Bragg peaks were first noticed in the recorded spectra during the second heating. This is in agreement with the DSC scans of Fig. 3. Linear fits of the glassy and supercooled liquid regions of the data from the second heating run were applied and the volumetric coefficients of thermal expansion $\gamma_{\text {glass }}^{x \text {-ray }}=5.46 \times 10^{-5} \mathrm{~K}^{-1}$ and $\gamma_{\text {SCL }}^{\mathrm{x} \text {-ray }}=1.30 \times 10^{-4} \mathrm{~K}^{-1}$ determined. The corresponding linear thermal expansion coefficients are determined through the relation $\gamma \approx 3 \alpha$, as $\alpha_{\text {glass }}^{\mathrm{x} \text {-ray }}=1.82 \times 10^{-5} \mathrm{~K}^{-1}$ and $\alpha_{\mathrm{SCL}}^{\mathrm{x} \text {-ray }}=$ $4.33 \times 10^{-5} \mathrm{~K}^{-1}$.

The trend in $\left[Q_{1}\left(T_{0}\right) / Q_{1}(T)\right]^{3}$ of the as-cast sample during the first heating run does not show completely linear behavior, however, over the entire temperature range up to $T_{g}$. In fact, a small change in slope was observed at around $50^{\circ} \mathrm{C}$, which is absent in the subsequent cooling and second heating runs. In order to highlight this subtle change, the difference between the first and second heating runs $\Delta$ is plotted in the inset of Fig. 6 (green circles). In this plot, the changes are more apparent and a distinct onset and maximum are observed at $\sim 50^{\circ} \mathrm{C}$ and $85^{\circ} \mathrm{C}$, respectively. These features observed in $\Delta$ are in accord with those seen in the experimental DMA and DSC/MDSC data of Figs. 1, 3, and 4.

In order to observe the subtle structural changes occurring on the nearest-neighbor length scale, we calculated the reduced pair distribution function $G(r)$ through a sine Fourier transformation of $S(Q)$ in the wave vector range 


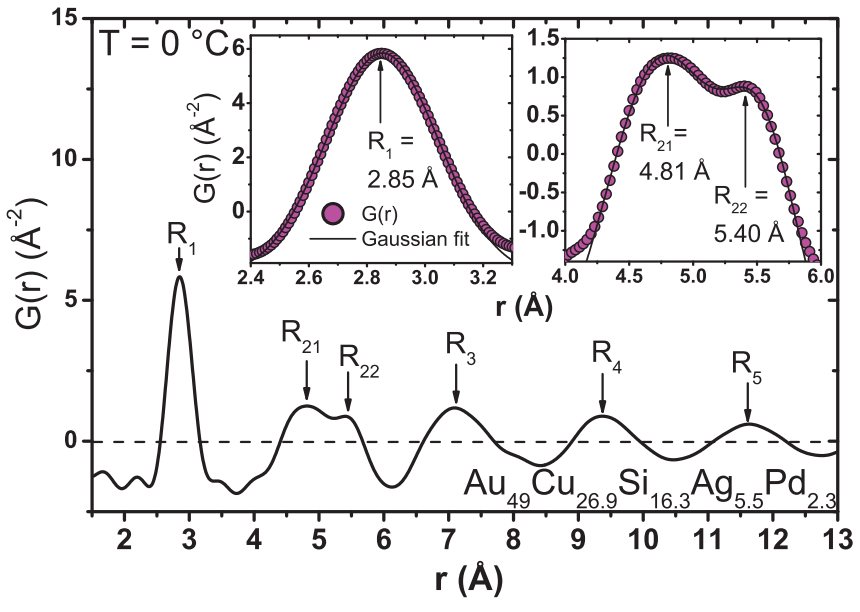

FIG. 7. (Color online) Reduced pair distribution function $G(r)$ of an as-cast sample of $\mathrm{Au}_{49} \mathrm{Cu}_{26.9} \mathrm{Si}_{16.3} \mathrm{Ag}_{5.5} \mathrm{Pd}_{2.3}$ calculated from the $S(Q)$ at $T_{0}=0{ }^{\circ} \mathrm{C}$. The peak maxima are labeled as $R_{i}$, where $i=1-5$. The first $G(r)$ peak $R_{1}$ (magenta circles, left inset) was fitted with a Gaussian function (solid line, left inset). The second split speak ( $R_{21}$ and $R_{22}$, right inset) was fitted with a sum of two Gaussians.

$$
\begin{aligned}
0 \leqslant Q \leqslant 14 \AA^{-1} & \text { by } \\
G(r) & =4 \pi r\left[\rho(r)-\rho_{0}\right] \\
& =\frac{2}{\pi} \int Q[S(Q)-1] \sin r Q d Q,
\end{aligned}
$$

where $\rho(r)$ is the atomic pair density distribution function and $\rho_{0}$ is the average atomic density.

Figure 7 shows the $G(r)$ of the $\mathrm{Au}_{49} \mathrm{Cu}_{26.9} \mathrm{Si}_{16.3} \mathrm{Ag}_{5.5} \mathrm{Pd}_{2.3}$ $\mathrm{BMG}$ in its as-cast state at a temperature of $0{ }^{\circ} \mathrm{C}$. To ensure satisfactory resolution of these fine structural changes, it is necessary to perform the Fourier transformation on as wide a $Q$ range as possible. $G(r)$ provides information about how the atoms are distributed and displays peaks at positions where pairs of atoms are separated with high probability. Similar to the total $S(Q)$, the total $G(r)$ of this alloy is the weighted sum of all 15 partial reduced pair distribution functions. The first peak $R_{1}$ is observed at $2.85 \AA$ at $0{ }^{\circ} \mathrm{C}$ and reflects predominantly the $\mathrm{Au}-\mathrm{Au}$ atomic separation. This is smaller than twice the Goldschmitt radius [36] for fcc $\mathrm{Au}\left(r_{\mathrm{Au}}=\right.$ $1.44 \AA$ ), which suggests a relatively close packing of the $\mathrm{Au}$ atoms. The changes in position of the peaks labeled $R_{1}$ through $R_{5}$ were tracked by fitting the experimental data (magenta circles, insets in Fig. 7) with a Gaussian function (solid line, left inset in Fig. 7). At around $5 \AA$, a splitting of the second $G(r)$ peak is observed. This splitting has also been observed in a similar $\mathrm{Au}_{65} \mathrm{Cu}_{18} \mathrm{Si}_{17} \mathrm{BMG}$ alloy [37]. The positions of the two subpeaks $R_{21}$ and $R_{22}$ were determined by fitting with a sum of two Gaussians (see right inset in Fig. 7).

\section{DISCUSSION}

\section{A. Dynamic $\beta$ relaxation in $\mathrm{Au}_{49} \mathrm{Cu}_{26.9} \mathrm{Si}_{16.3} \mathrm{Ag}_{5.5} \mathrm{Pd}_{2.3}$ and the nature of sub- $T_{g}$ endotherms}

Figure 1 shows the results of isochronal DMA tests performed on as-cast samples of the $\mathrm{Au}_{49} \mathrm{Cu}_{26.9} \mathrm{Si}_{16.3} \mathrm{Ag}_{5.5} \mathrm{Pd}_{2.3}$ $\mathrm{BMG}$ at various loading frequencies. Common to each set of data is the excess wing in $E^{\prime \prime}$ appearing in the low-temperature range from $\sim 50{ }^{\circ} \mathrm{C}$ up to the dynamic $\alpha$-relaxation peak at $\sim 130^{\circ} \mathrm{C}$. Additionally, a shoulder or broad hump appearing at $\sim 80^{\circ} \mathrm{C}-110^{\circ} \mathrm{C}$ is identified in all three sets of data as a weak $\beta$-relaxation peak superimposed onto the low-temperature tail of the $\alpha$ relaxation. This is in contrast to other BMG-forming systems, most notably some of those in the La-Al-Ni family, which show a pronounced and distinct $\beta$-relaxation peak in the DMA loss curve $[19,26]$. The dynamic behavior shown in Fig. 1 is more comparable to that observed in some $\mathrm{Zr}$ - and $\mathrm{Cu}$-based BMGs, in which only a faint shoulder in the DMA loss curve has been observed as well [20].

It has been recently discussed how the unique chemical interactions between the constituent elements of a glassy alloy influences the behavior of $E^{\prime \prime}$ during the dynamic $\beta$-relaxation temperature regime [38]. In particular, a large negative and similar enthalpy of mixing $\Delta H_{\text {mix }}$ was identified as a common factor in systems with pronounced $\beta$-relaxation peaks. Large differences in $\Delta H_{\text {mix }}$, on the other hand, were associated with those systems, in which only faint shoulders or excess wings were reported. Indeed, using the empirical models for $\Delta H_{\text {mix }}$ [39], one can identify in $\mathrm{Au}_{49} \mathrm{Cu}_{26.9} \mathrm{Si}_{16.3} \mathrm{Ag}_{5.5} \mathrm{Pd}_{2.3}$ those chemical affinities that are particularly strong, e.g., $\Delta H_{\mathrm{mix}}^{\mathrm{Au}-\mathrm{Si}}=-30 \mathrm{~kJ} / \mathrm{g}$ atom and $\Delta H_{\mathrm{mix}}^{\mathrm{Cu}-\mathrm{Si}}=$ $-19 \mathrm{~kJ} / \mathrm{g}$ atom, and those that are comparably weak, e.g., $\Delta H_{\mathrm{mix}}^{\mathrm{Au}-\mathrm{Cu}}=-9 \mathrm{~kJ} / \mathrm{g}$ atom, $\Delta H_{\mathrm{mix}}^{\mathrm{Au}-\mathrm{Ag}}=-6 \mathrm{~kJ} / \mathrm{g}$ atom, and $\Delta H_{\text {mix }}^{\mathrm{Cu}-\mathrm{Ag}}=+2 \mathrm{~kJ} / \mathrm{g}$ atom. It should, however, be noted that mixing in a multicomponent system is necessarily temperature and composition dependent and that interactions due to the unique electronic structure of each atomic species are generally not accounted for in such models. Nevertheless, the behavior of the DMA data presented in Fig. 1 appears to be in accord with the general rule summarized in Ref. [38], although more material-specific chemical interactions may need to be considered, as will be discussed later in Sec. IV D.

Although no unanimous consensus has been reached on the exact structural origin of the slow $\beta$ relaxation, its ubiquity has been amply documented in many classes of amorphous solids $[16,22,40]$. The slow $\beta$ relaxation was originally attributed by Johari and Goldstein [16] to the localized movement of atoms or molecules in a mechanically rigid glassy structure, facilitated by density fluctuations frozen-in from the supercooled liquid. With respect to BMGs, this is often discussed in terms of free volume, where the slow $\beta$ relaxation is thought to occur in locally higher free volume regions that exist within a denser glassy matrix [23,26,41]. Furthermore, a broad relaxation time spectrum in glasses is inexorably linked to the slow $\beta$ relaxation [16] and is evident in $\mathrm{Au}_{49} \mathrm{Cu}_{26.9} \mathrm{Si}_{16.3} \mathrm{Ag}_{5.5} \mathrm{Pd}_{2.3}$ by the pronounced sub- $T_{g}$ endotherm seen in the DSC and MDSC curves of Figs. 3 and 4. In fact, similar DSC heat flow behavior has been reported in a variety of other glass formers as well [42-44], and calorimetric studies on a series of organic and molecular glasses have already shown that a broad sub- $T_{g}$ endotherm is associated with the kinetic unfreezing of the dynamic $\beta$ relaxation [45-47]. Additionally, in a study of long-term aging of selenide glasses, for example, Chen et al. identified pronounced sub- $T_{g}$ endotherms as being the result of compacted regions of the Se backbone coalescing with 
the surrounding noncompacted regions [42]. Although the bonding mechanisms are fundamentally different between BMGs and selenide glasses, the premise of a heterogeneous glassy structure is nevertheless fundamental to both.

In addition, it has been observed that a certain annealing time is required at temperatures far below $T_{g}$ before the sub- $T_{g}$ endotherm is seen in a calorimetric up scan $[42,43,48]$. Macroscopically, after some excess enthalpy is lost during aging at these low temperatures, it is completely recovered before $T_{g}$ upon heating and manifests itself as a broad, endothermic DSC peak in the temperature range $\sim 75 \%$ to $80 \%$ of the caloric $T_{g}$. This scenario was observed in polyvinyl chloride by Berens and Hodge [43], who concluded that sub- $T_{g}$ endotherms are the consequence of short-time portions of a broad relaxation time spectrum coming to equilibrium at temperatures far below $T_{g}$. Similarly, crossover effects in elastic modulus, as seen in Fig. 2, have been observed during relaxations of thin ribbon metallic glass samples; however, previously this effect has only been observed after preannealing well below the final annealing temperature $[10,11]$. It has been reasoned that the low-temperature preannealing step establishes a given amount of CSRO, which then disorders during the initial period of the higher-temperature anneal, causing a decrease in the elastic modulus. The elastic modulus then gradually recovers, as CSRO is reestablished [15]. Based on these collective results, we hypothesize that, due to its low value of $T_{g}, \mathrm{Au}_{49} \mathrm{Cu}_{26.9} \mathrm{Si}_{16.3} \mathrm{Ag}_{5.5} \mathrm{Pd}_{2.3}$ ages in the necessary low-temperature range during the casting and cooling process leading to a certain amount of CSRO and hence to the calorimetric behavior of the as-cast sample shown in Figs. 3 and 4(a) and crossover effect of modulus in Fig. 2. Thus, behavior normally only seen in low-temperature annealed samples is here observed in as-cast samples.

A broad spectrum of relaxation times in the glassy state is a long-observed feature of metallic glasses $[44,49]$. The question still remains, however, whether the observed phenomena normally attributed to the slow $\beta$ relaxation in BMGs belong to a separate, secondary relaxation mode or to faster portions of a wide $\alpha$-relaxation spectrum. For example, a recent study of hyperquenched ribbons of glassy $\mathrm{Mg}_{65} \mathrm{Cu}_{25} \mathrm{Y}_{10}$ by Pineda et al. [50] reports a low-temperature shoulder in the DMA loss modulus, similar to that shown in Fig. 1, and it was found that this shoulder could be suppressed by slowly cooling from the supercooled liquid. It was concluded that this was not attributed to a distinct secondary, or $\beta$, relaxation, but rather to the access of the system to a broad $\alpha$-relaxation process. With regard to the $\mathrm{Au}_{49} \mathrm{Cu}_{26.9} \mathrm{Si}_{16.3} \mathrm{Ag}_{5.5} \mathrm{Pd}_{2.3} \mathrm{BMG}$ investigated in this paper, we see similar behavior in the MDSC curves of Fig. 4. More specifically, the reversing, or thermodynamic part of the MDSC heat flow curve, shows a distinct endothermic change in slope beginning at $\sim 60^{\circ} \mathrm{C}$ and is apparent in both the first and second heating curves [arrows in Figs. 4(b) and 4(c)]. The sub- $T_{g}$ endotherm, on the other hand, appears to be mostly irreversible, as it is almost completely absent in the second heating curve of the overall DSC heat flow signal of Fig. 4(a). However, a small sub- $T_{g}$ endotherm is nevertheless able to be resolved in the nonreversing part of the MDSC signal of Fig. 4(c) (second heating), albeit with a much smaller associated enthalpy (shaded areas in Fig. 4). We thus identify this as the kinetic unfreezing of the loose portions of the BMG atomic structure that were partially arrested in this temperature range during slow cooling from the supercooled liquid.

The $\alpha$ relaxation is characterized by highly cooperative structural rearrangements usually having an apparent activation energy of $\sim 400-500 \mathrm{~kJ} / \mathrm{g}$ atom $(\sim 4-5 \mathrm{eV})$ near the glass transition in metallic glass systems [26,44,51]. In contrast to this, the $\beta$ relaxation is thought to correspond to more localized, faster atomic rearrangements, which persist to temperatures far below the caloric glass transition $[18,52]$. The apparent activation energy of the slow $\beta$ relaxation $E_{\beta}$ is significantly smaller than that of the $\alpha$ relaxation and the following empirical correlation between $E_{\beta}$ and $T_{g}$ been proposed [18]:

$$
E_{\beta} \approx 26( \pm 2) R T_{g}
$$

where $R$ is the universal gas constant. Taking the value of $T_{g}=123{ }^{\circ} \mathrm{C}(396 \mathrm{~K})$ measured in DSC at a heating rate of $0.33 \mathrm{~K} / \mathrm{s}$, we estimate $E_{\beta}$ via the above correlation as $85.6 \pm$ $6.7 \mathrm{~kJ} / \mathrm{g}$ atom $(\sim 0.89 \mathrm{eV})$.

Experimentally, $E_{\beta}$ can be determined through the temperature dependence of the dynamic $\beta$-relaxation peak observed in DMA at varying test frequencies. However, the DMA loss curves in Fig. 1 show only a faint shoulder indicating a dynamic $\beta$ relaxation; as such, an unambiguous determination of the peak temperature is not possible. As an alternative to determining the apparent activation energy for the $\beta$ relaxation from the DMA loss curves, as-cast amorphous samples of $\mathrm{Au}_{49} \mathrm{Cu}_{26.9} \mathrm{Si}_{16.3} \mathrm{Ag}_{5.5} \mathrm{Pd}_{2.3}$ were measured in the DSC at different heating rates and an apparent activation energy $E_{\beta}^{\prime}$ was determined from fitting an Arrhenius equation to the experimentally observed heating rate dependence of the peak temperature of the sub- $T_{g}$ endotherm $T_{p}$. The DSC up scans and observed heating rate dependence of $T_{p}$ are shown in Fig. 8. The results in Fig. 8(b) show that the heating rate dependence of $T_{p}$ can be well described by an Arrhenius law with an apparent activation energy of $E_{\beta}^{\prime}=88.9 \pm 6.0 \mathrm{~kJ} / \mathrm{g}$ atom $(\sim 0.92 \mathrm{eV})$, which is in excellent agreement with the activation energy estimated using Eq. (8).

We therefore propose that the dynamic $\beta$ relaxation and sub$T_{g}$ endotherm observed in this glassy alloy both involve similar mechanisms of atomic rearrangement. Indeed, sub- $T_{g}$ endotherms have been observed in both the as-cast and annealed states of other BMG-forming alloys as well [44,48,53,54]; to date, however, a mechanistic connection with the dynamic $\beta$ relaxation had not been made. Not surprisingly, the other BMGs exhibiting similar sub- $T_{g}$ endotherms in their as-cast states are also alloys with the low values of $T_{g}$ and hence low activation energies for the atomic rearrangements responsible for the $\beta$ relaxation. This effect is therefore more pronounced in these types of alloys since the aging regime lies close to the ambient temperature range and the glassy alloy is inadvertently and often unavoidably exposed to these temperatures during casting. On the other hand, alloys with higher values of $T_{g}$ must be intentionally aged in the sub- $T_{g}$ regime before an endotherm is observed during reheating [44,48,54]. It should furthermore be pointed out that the heating rate dependence of the sub- $T_{g}$ endotherm observed in Fig. 8 would necessarily be different depending on the thermal history of the sample. That is, the value of $E_{\beta}^{\prime}$ in Fig. 8(b) should be taken to reflect the relaxation spectrum of the as-cast material only. In fact, 
(a)
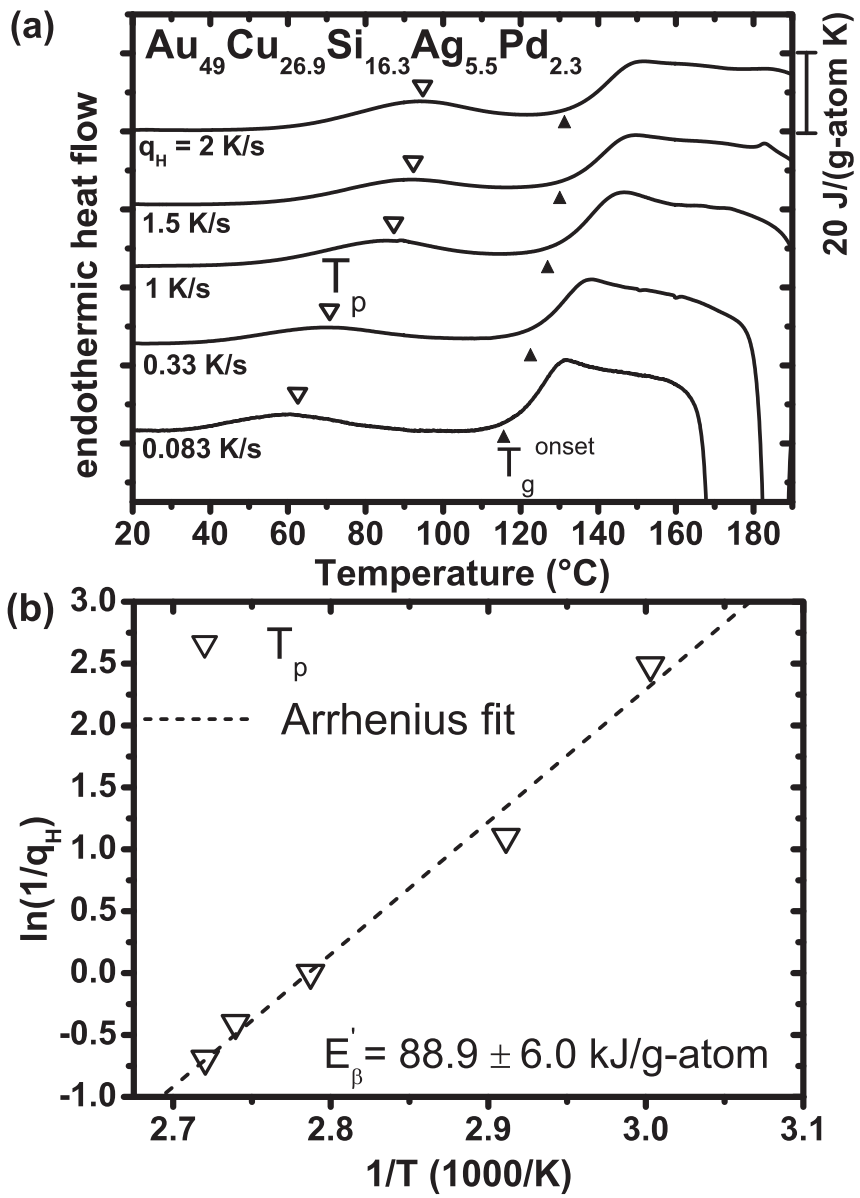

FIG. 8. (a) DSC up scans (endotherms up) of as-cast samples of $\mathrm{Au}_{49} \mathrm{Cu}_{26.9} \mathrm{Si}_{16.3} \mathrm{Ag}_{5.5} \mathrm{Pd}_{2.3}$ employed at various heating rates $q_{H}$. The peak temperature of the sub- $T_{g}$ endotherm $T_{p}$ is indicated by the downward triangle. The onset of the caloric glass transition $T_{g}^{\text {onset }}$ is marked by the upward solid triangle. (b) Arrhenius fit (dashed line) of the temperature dependence of the inverse heating rate (downward triangles) yielding an apparent activation energy of $E_{\beta}^{\prime}=88.9 \pm$ $6.0 \mathrm{~kJ} / \mathrm{g}$ atom $(\sim 0.92 \mathrm{eV})$.

Vianco and Li investigated sub- $T_{g}$ endotherms in a Ni-based metallic glass [48] and concluded that the value of $E_{\beta}^{\prime}$ obtained from calorimetric experiments increases as the relaxation time spectrum is shifted to longer times due to annealing.

In consideration of the experimental data presented and the other results cited in this section, we suggest that the underlying mechanisms responsible for the dynamic $\beta$ relaxation observed in the DMA also contribute to the calorimetric behavior shown in Figs. 3, 4, and 8. That is, aging at temperatures close to the $\beta$-relaxation regime will induce structural relaxation in the loose or weakly bonded regions of the glassy structure while the matrix remains comparatively immobile. As a consequence, structural recovery occurs in these regions when the glass is reheated through the $\beta$ relaxation temperature regime. This manifests itself as the broad sub- $T_{g}$ endotherm apparent in DSC up scans and completely separable as the nonreversing MDSC component. Meanwhile, the change in slope observed in the reversing part of the MDSC signal at $\sim 60^{\circ} \mathrm{C}$ is related to the reversible relaxation spectrum as a manifestation of a long tail of the $\alpha$ relaxation.

\section{B. Atomic-scale structural changes during $\beta$ relaxation}

The high-energy $x$-ray scattering techniques used to monitor, in situ, the effects of thermal cycling on this BMG give information about the atomic-scale changes occurring in the glassy structure and provide insight into the structural origins of the slow $\beta$ relaxation in BMGs. The structural data presented in Fig. 6 show the normalized atomic volumetric expansion $V / V_{0}$ calculated from the relation in Eq. (6). Indeed, there is a noticeable difference, beginning at $\sim 50{ }^{\circ} \mathrm{C}$, in the data from the first heating run when compared with those of the second heating run, after having slowly cooled from the supercooled liquid (inset Fig. 6). Most notably, in the low-temperature region from $0{ }^{\circ} \mathrm{C}-50^{\circ} \mathrm{C}$, there is an almost insignificant difference between the $\left[Q_{1}\left(T_{0}\right) / Q_{1}(T)\right]^{3}$ values corresponding to each run. Specifically, we compare the start of the first heating with the start of the second heating (at $0^{\circ} \mathrm{C}$ ) and determine that the decrease in excess free volume of this BMG after slowly cooling from the supercooled liquid is on the order of $0.025 \%$. Compared to a free volume decrease of $0.3 \%$ observed in samples from an as-cast rod of $\mathrm{La}_{62} \mathrm{Al}_{14}\left(\mathrm{Cu}_{5 / 6} \mathrm{Ag}_{1 / 6}\right)_{14} \mathrm{Ni}_{5} \mathrm{Co}_{5}$ [55], $0.5 \%$ in an as-spun ribbon of $\mathrm{Mg}_{65} \mathrm{Cu}_{25} \mathrm{Y}_{10}$ [56], and $0.2 \%$ in as-spun ribbons of $\mathrm{Pd}_{40} \mathrm{Cu}_{30} \mathrm{Ni}_{10} \mathrm{P}_{20}$ [33], this difference appears extremely small and is likely due to the initially low excess free volume arising from the slow cooling rates of the tilt-casting procedure coupled with unavoidable aging at ambient and elevated temperatures during production of the amorphous samples.

In order to glean more detailed information about the structural changes occurring, we analyzed two other profile parameters determined from the pseudo-Voigt peak function in Eq. (5); namely, the reduced height of the first structure factor maximum $S\left(Q_{1}\right) / S\left[Q_{1}\left(T_{0}\right)\right]$ and the reduced FWHM $w / w\left(T_{0}\right)$. Other studies on BMG systems have shown these quantities to be useful as complementary metrics to the peak position [37,55,57]. In a single-component system, the FWHM can characterize the degree of ordering, where a broader FWHM indicates a more disordered state. However, in a multicomponent system, the broadening or narrowing of the FHWM is influenced by the shifting in the positions of the multiple underlying peaks belonging to each of the partial structure factors. The individual $\mathrm{x}$-ray scattering weights of the constituent atomic pairs determine the contribution of the partial structure factor to the observed total $S(Q)$. In the case of $\mathrm{Au}_{49} \mathrm{Cu}_{26.9} \mathrm{Si}_{16.3} \mathrm{Ag}_{5.5} \mathrm{Pd}_{2.3}$, there are a total of 15 partial structure factors, with the weighting factors $W_{\mathrm{Au}-\mathrm{Au}}=0.54$ and $W_{\mathrm{Au}-\mathrm{Cu}}=0.22$ being the most dominant [Eq. (4)].

Figure 9 shows the temperature evolution of $S\left(Q_{1}\right) / S\left[Q_{1}\left(T_{0}\right)\right]$ and $w / w\left(T_{0}\right)$ during thermal cycling. From each data set it is apparent that, with increasing temperature, the structure factor maximum intensity decreases concomitantly with a broadening in the FWHM. In general, the reduction in peak intensity during heating can be attributed to the Debye-Waller factor; however, the abrupt change in slope observed at $T_{g}^{\mathrm{x} \text {-ray }}$ is a clear indication of the atomic-scale structural rearrangements occurring at the glass transition. The trend in the FWHM reverses, however, in the temperature range from $100^{\circ} \mathrm{C}$ to $125^{\circ} \mathrm{C}$, and is magnified in the inset of Fig. 9(b). In this temperature range, the first structure factor maximum begins to narrow along with a slight 


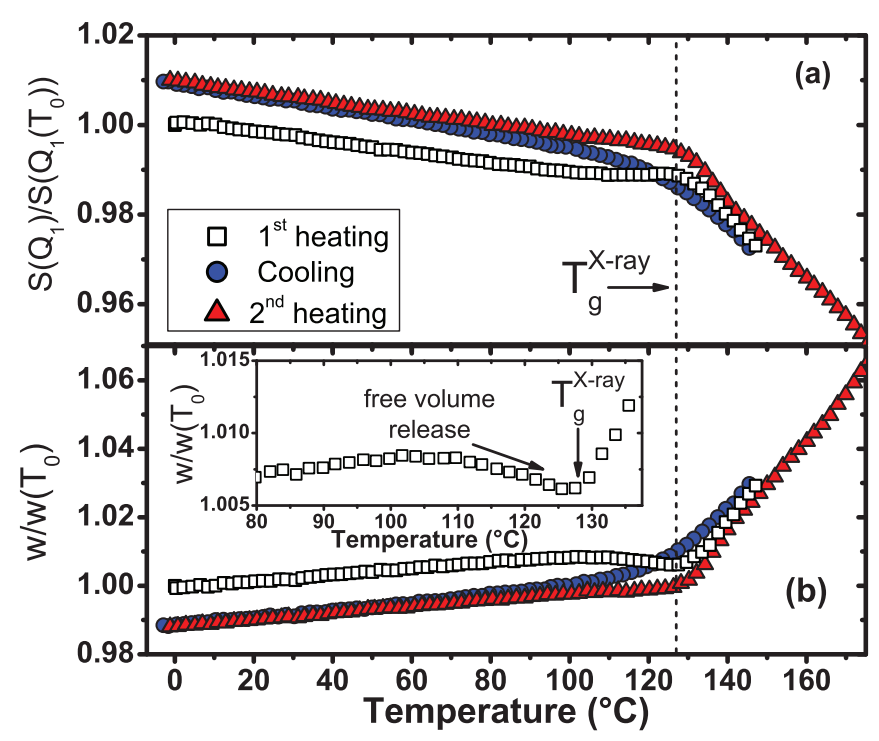

FIG. 9. (Color online) (a) Reduced height of the first structure factor maximum $S\left(Q_{1}\right) / S\left[Q_{1}\left(T_{0}\right)\right]$ and (b) reduced FWHM $w / w\left(T_{0}\right)$ during thermal cycling. The glass transition $T_{g}^{\mathrm{x} \text {-ray }}$ is apparent at $\sim 129^{\circ} \mathrm{C}$ in both peak parameters. The inset in (b) shows a magnification of $w / w\left(T_{0}\right)$, where the release of excess free volume just prior to the glass transition is reflected in a sharpening of the FWHM. In both peak parameters, a difference of $\sim 1 \%$ between the first and second heating runs at $T_{0}$ can be ascertained.

increase in the peak intensity. This corresponds to the release of frozen-in excess free volume prior to the glass transition, causing an increase in topological order. This is even more apparent in samples containing a substantial amount of excess free volume and topological disorder through rapid quenching or mechanical treatment [57]. Furthermore, the DSC data of Fig. 3 show an exothermic dip of the heat flow curve in this same temperature range, which is also coincident with the observed trend in the inset of Fig. 9(b).

In Fig. 9, we observe no noticeable deviation in either the peak height or the FWHM trend in the temperature region of the slow $\beta$ relaxation, in contrast to the change in slope observed in the $\left[Q_{1}\left(T_{0}\right) / Q_{1}(T)\right]^{3}$ data presented in Fig. 6. The overall broadening of the FWHM during heating is affected by both the broadening and the shifting in the peak positions of the underlying partial structure factors. Since no anomaly is visible in the data of Fig. 9(b), we conclude that this is due to the peak positions of the dominant partial structure factors, in this case, $S_{\mathrm{Au}-\mathrm{Au}}(Q)$ and $S_{\mathrm{Au}-\mathrm{Cu}}(Q)$, changing in unison with each other during heating. It is possible that the peak positions of other atomic pairs behave differently with temperature, although it is difficult to speculate due to their minute contributions to the total $S(Q)$. We do, however, notice a significant difference between the values of the reduced height of the first structure factor maximum and FWHM taken from the first and second heating runs at $T=0{ }^{\circ} \mathrm{C}$. That is, at the beginning of the second heating run, the reduced heights of the first structure factor maximum and FWHM have increased and decreased, respectively, by $\sim 1 \%$. This could be due to an irreversible reduction of the disorder that was frozen-in during casting. Comparing this value with the cube root of the almost negligible change in free volume observed between

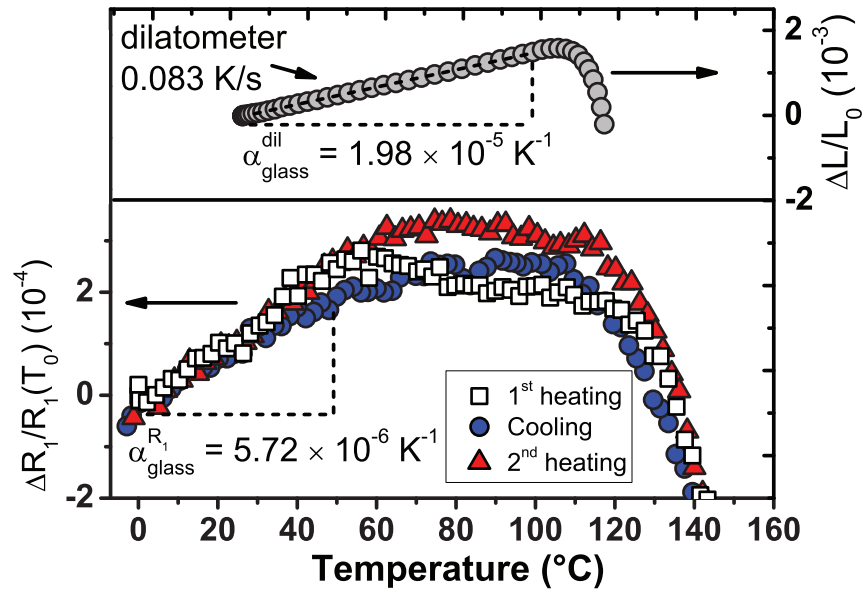

FIG. 10. (Color online) Reduced first $G(r)$ peak position $\Delta R_{1} / R_{1}\left(T_{0}\right)$ during thermal cycling (bottom). All three sets of data share a similar thermal expansion coefficient of $\alpha_{\text {glass }}^{R_{1}}=5.72 \times$ $10^{-6} \mathrm{~K}^{-1}$ up to $\sim 60^{\circ} \mathrm{C}$. The dilatometric thermal expansion data (shaded circles, top) are given as comparison and the linear thermal expansion coefficient is determined as $\alpha_{\text {glass }}^{\text {dil }}=1.98 \times 10^{-5} \mathrm{~K}^{-1}$.

each heating run in Fig. 6, i.e., $\left[\Delta V\left(T_{0}\right) / V\left(T_{0}\right)\right]^{1 / 3} \sim 0.025 \%$ or $\Delta L\left(T_{0}\right) / L\left(T_{0}\right) \sim 0.3 \%$, we notice that these two quantities differ by almost an order of magnitude. In other words, while the change in length scale corresponding to the structural state between the two heating runs is only $\sim 0.3 \%$, the change in correlation appears to be much larger, $\sim 1 \%$. It is possible that this discrepancy is due to an irreversible increase in CSRO that had occurred after the first heating run since changes in the CSRO do not significantly affect the free volume $[3,58]$.

Through Eq. (7), a real-space picture of the atomic changes occurring during thermal cycling of this BMG is provided. Figure 10 shows the temperature evolution of the reduced first $G(r)$ peak position $\Delta R_{1} / R_{1}\left(T_{0}\right)$ during the first heating, cooling, and second heating scans (open squares, blue circles, and red triangles, respectively). One prominent feature of the nearest-neighbor separation in $\mathrm{Au}_{49} \mathrm{Cu}_{26.9} \mathrm{Si}_{16.3} \mathrm{Ag}_{5.5} \mathrm{Pd}_{2.3}$ is the existence of two distinct temperature regimes of thermal expansion below the glass transition. In particular, the nearestneighbor thermal expansion coefficient $\alpha_{\text {glass }}^{R_{1}}=5.72 \times$ $10^{-6} \mathrm{~K}^{-1}$ is the same for all three thermal cycles up to $\sim 50{ }^{\circ} \mathrm{C}$, after which a marked change in slope of $\Delta R_{1} / R_{1}\left(T_{0}\right)$ is noticed. More specifically, the slope of $\Delta R_{1} / R_{1}\left(T_{0}\right)$ becomes negative during the first heating, while during the second heating, the slope vanishes and $\Delta R_{1} / R_{1}\left(T_{0}\right)$ remains more or less constant up until $\sim 110^{\circ} \mathrm{C}$. It is now evident that there are distinct reversible changes occurring in the atomic-scale structure at $\sim 50{ }^{\circ} \mathrm{C}$. Furthermore, the irreversible changes associated with the broad sub- $T_{g}$ endotherm (Figs. 3 and 4 ) are reflected in the sudden negative change in slope of $\Delta R_{1} / R_{1}\left(T_{0}\right)$ during the first heating and correspond to an average reduction in the nearest-neighbor separation distance. Close to and above the glass transition $\left(T>110^{\circ} \mathrm{C}\right) \alpha_{\text {glass }}^{R_{1}}$ becomes increasingly negative, showing again a contraction of the average atomic distance in the first coordination shell.

The atomic-scale rearrangements in this BMG are compared with the overall macroscopic thermal expansion, as 


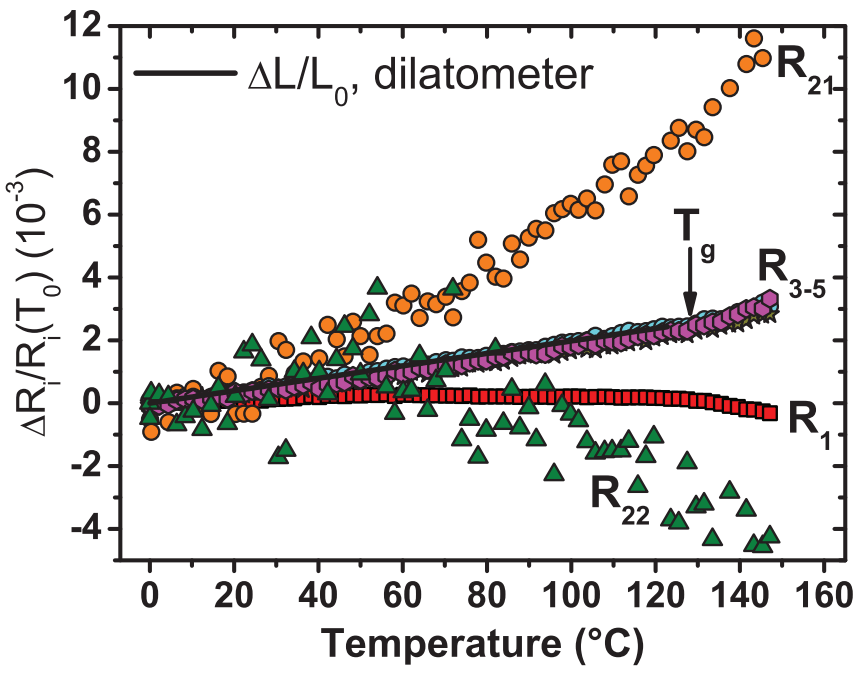

FIG. 11. (Color online) Relative changes of the $G(r)$ maxima during heating $\Delta R_{i} / R_{i}\left(T_{0}\right)$, where $i=1-5$. The macroscopic linear thermal expansion curve $\Delta L / L_{0}$ taken from dilatometry measurements is reproduced here (solid line). The glass transition $T_{g}$ is evident by the negative and positive changes in slope of $R_{1}$ and $R_{3-5}$, respectively.

determined in the dilatometer (shaded circles, Fig. 10). After correction to the thermal expansion of the sample holder and a reference of pure $\mathrm{Cu}$, the macroscopic linear thermal expansion coefficient of the glassy state was determined to be $\alpha_{\text {glass }}^{\text {dil }}=$ $1.98 \times 10^{-5} \mathrm{~K}^{-1}$, and is in good agreement with the value of $2.13 \times 10^{-5} \mathrm{~K}^{-1}$ determined for a similar $\mathrm{Au}_{50} \mathrm{Cu}_{25.5} \mathrm{Si}_{17} \mathrm{Ag}_{7.5}$ BMG [59]. The value of $\alpha_{\text {glass }}^{\text {dil }}$ determined here is around an order of magnitude greater than the thermal expansion coefficient observed on the nearest-neighbor length scale $\alpha_{\text {glass }}^{R_{1}}$, and a similar finding in the $\mathrm{Cu}_{65} \mathrm{Zr}_{35}$ BMG has been reported by Mattern et al. [60] Moreover, we find good agreement between the linear thermal expansion coefficient of the glass as determined from the change in $Q_{1}\left(\alpha_{\text {glass }}^{\mathrm{XRD}}=1.82 \times 10^{-5} \mathrm{~K}^{-1}\right)$ and that measured in the dilatometer. However, in contrast to the change of slope in $\left[Q_{1}\left(T_{0}\right) / Q_{1}(T)\right]^{3}$ observed during the first heating run in Fig. 6, no anomalous behavior is noticed in the dilatometer signal in the range of the $\beta$ relaxation. It is now apparent that distinct structural changes are occurring on length scales not represented in the macroscopic thermal expansion measured in the dilatometer. The differences in thermal expansion on varying length scales are compared in Fig. 11 through the relative changes with temperature of the other maxima in $G(r), \Delta R_{i} / R_{i}\left(T_{0}\right)$, where $i=1-5$. The macroscopic linear thermal expansion $\Delta L / L_{0}$ determined in the dilatometer is shown here for comparison (solid black line).

When compared to the scale of the changes in the other maxima, the change in $R_{1}$ with temperature appears almost negligible (red squares). Additionally, the changes in $R_{21}$ (orange circles) and $R_{22}$ (green triangles) are observed to deviate significantly from the macroscopic thermal expansion, while the changes in $R_{3-5}$ are found to be in agreement. Even though there is a larger scatter in $R_{22}$, a distinct change in slope is nevertheless observed at $\sim 60{ }^{\circ} \mathrm{C}$. It would thus appear that the structural changes occurring in the temperature regime of the $\beta$ relaxation are not only confined to the nearest neighborhood and can be observed on a length scale out to $\sim 5.5 \AA$. Furthermore, the glass transition is evident through the positive change of slope in $R_{3-5}$ at $\sim 130{ }^{\circ} \mathrm{C}$ and the slightly negative change of slope in $R_{1}$ at the same temperature. The macroscopic thermal expansion (solid black line in Fig. 11) is reflected predominantly by the thermal expansion of the medium-range order, given by $R_{3-5}(r>$ $7 \AA$ ), and is comparable to that observed in $\mathrm{Cu}_{65} \mathrm{Zr}_{35}$ [60].

The real-space structural data in Figs. 10 and 11 help to illuminate the aforementioned premise of atomic-scale structural heterogeneities in BMGs. Specifically, the differing thermal expansion behavior observed amongst the $G(r)$ maxima indicate that the atomic-scale structural changes do not occur uniformly on all length scales. This behavior is similar to what has been observed previously in melts of pure metals as well as the BMG-forming alloy $\mathrm{Zr}_{41.25} \mathrm{Ti}_{13.75} \mathrm{Ni}_{10} \mathrm{Cu}_{12.5} \mathrm{Be}_{22.5}$ [35,61]. Additionally, the large hysteresis between the first and second heating runs noticed in the thermal behavior of $R_{1}$ at $\sim 60^{\circ} \mathrm{C}$ (Fig. 10) is indicative of an irreversible structural change occurring in the as-cast state. Even though the thermal expansion of $R_{1}$ during the second heating run also changes slope around this temperature, the change in slope is more pronounced in the first heating run, which is also reflected in the large nonreversing sub- $T_{g}$ endotherm apparent in the first MDSC heating [Fig. 4(b)].

\section{Atomic-scale structural changes during low-temperature aging}

Figure 2 shows that significant changes in the Young's modulus are observed at room temperature in as-cast samples of $\mathrm{Au}_{49} \mathrm{Cu}_{26.9} \mathrm{Si}_{16.3} \mathrm{Ag}_{5.5} \mathrm{Pd}_{2.3}$ after isothermal annealing treatments at $37^{\circ} \mathrm{C}$ and $50^{\circ} \mathrm{C}$. Similar effects have also been reported in many other metallic glass systems by observing the time evolution of properties such as elastic moduli or Curie temperature during annealing at temperatures far below the caloric glass transition $[11,15,62]$.

We investigated this behavior on the atomic length scale by tracking the relative changes in the positions of the first maxima in $S(Q)$ and $G(r), Q_{1}\left(t_{0}\right) / Q_{1}(t)-1$, and $\Delta R_{1}(t) / R_{1}\left(t_{0}\right)$, respectively, during in situ annealing of an as-cast sample at $50{ }^{\circ} \mathrm{C}$. Figure 12 shows $Q_{1}\left(t_{0}\right) / Q_{1}(t)-1$ (blue circles) and $\Delta R_{1}(t) / R_{1}\left(t_{0}\right)$ (red squares) during an annealing time of $\sim 8000 \mathrm{~s}$ at $50^{\circ} \mathrm{C}$. It should be noted that the data corresponding to the heating ramp from $0{ }^{\circ} \mathrm{C}-50^{\circ} \mathrm{C}$ are not shown here and that the data points in Fig. 12 reflect a constant $( \pm 0.1 \mathrm{~K})$ sample temperature of $50^{\circ} \mathrm{C}$. A fast increase in the relative position of $Q_{1}$ is observed up to an annealing time of $\sim 500-1000 \mathrm{~s}$, followed by a slow decrease throughout the remainder of the experiment. On the nearest-neighbor atomic length scale, this is reflected in a similarly fast initial decrease in the relative peak position of $R_{1}$, followed by a slow recovery at longer annealing times. The minimum in $\Delta R_{1}(t) / R_{1}\left(t_{0}\right)$ at $\sim 1000 \mathrm{~s}$ is comparable to the observed minimum of $\sim 900 \mathrm{~s}$ observed in the Young's modulus measured at $50^{\circ} \mathrm{C}$ (Fig. 2).

Upon examining the other $G(r)$ maxima (Fig. 13), we observe that the relative changes in $R_{1}$ [red squares, Fig. 13(b)] and $R_{3-5}$ [magenta hexagons, cyan circles, and brown stars, respectively, Fig. 13(b)] are much smaller than those observed in $R_{21}$ and $R_{22}$ [orange circles and green triangles, respectively, 


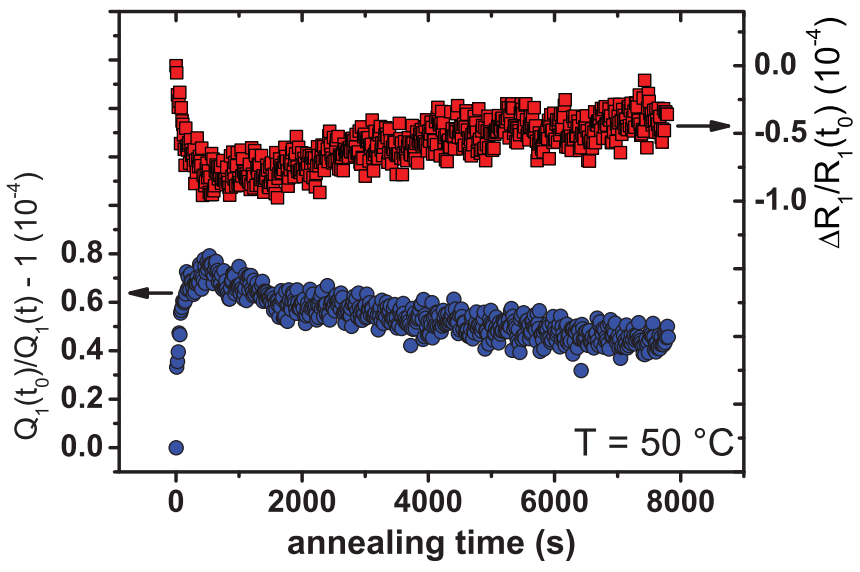

FIG. 12. (Color online) Relative changes in the first $S(Q)$ and $G(r)$ maxima, $Q_{1}\left(t_{0}\right) / Q_{1}(t)-1$ (blue circles) and $\Delta R_{1} / R\left(t_{0}\right)$ (red squares), respectively, as a function of annealing time at $50^{\circ} \mathrm{C}$. The data corresponding to the initial heating ramp from $0{ }^{\circ} \mathrm{C}-50^{\circ} \mathrm{C}$ are not shown here.

Fig. 13(a)], which appear to gradually increase and decrease, respectively, over the duration of the annealing. It would appear that a subtle increase in the relative position of $R_{3}$ can also be discerned; however, due to the relative scatter in these data points, it is difficult to certify. Additionally, the difference in scaling between Figs. 13(a) and 13(b) should be taken into consideration when interpreting the atomic-scale structural changes during annealing. That is, the overall decrease in $R_{22}$ is almost an order of magnitude greater than the fast changes observed in $R_{1}$; however, the scatter observed in $R_{21}$ and $R_{22}$ is greatly magnified as well. For comparison, the relative change in $R_{1}$ is given in both Figs. 13(a) and 13(b).

The data presented in Figs. 12 and 13 show a definite fast relaxation process occurring on the nearest-neighbor length

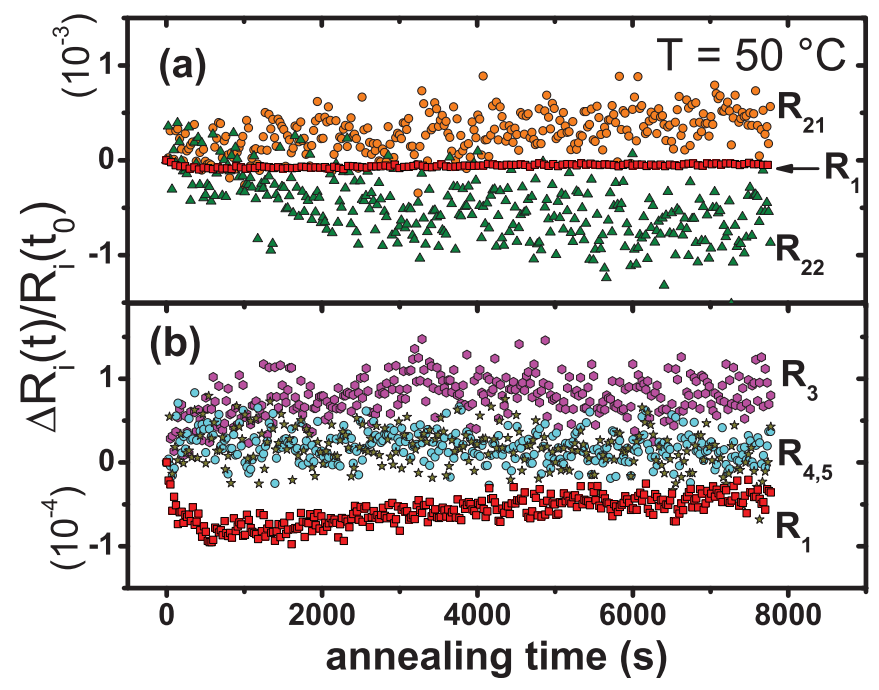

FIG. 13. (Color online) Evolution of the positions of the different $G(r)$ peak maxima, $\Delta R_{i}(t) / R\left(t_{0}\right)$, where $i=1-5$, with annealing time at $50^{\circ} \mathrm{C}$. Note the scaling difference of $10^{-3}$ and $10^{-4}$ in (a) and (b), respectively. For comparison, the data corresponding to $R_{1}$ are shown in both (a) and (b). scale within $\sim 1000 \mathrm{~s}$ during annealing at $50^{\circ} \mathrm{C}$, after which slower changes begin to occur on the more intermediate length scales, given by, e.g., the relative changes in $R_{21}$ and $R_{22}$ [Fig. 13(a)]. However, on the length scales reflecting the medium-range order $R_{3-5}$, hardly any changes in the relative peak positions are observed. This behavior mirrors the microscopic thermal expansion data of Fig. 11. Specifically, we observe in both isochronal and isothermal experiments small, yet distinct, changes in $R_{1}$ concomitant with a much larger increase and decrease in the relative positions of $R_{21}$ and $R_{22}$, respectively. It was established in the previous section that the macroscopic thermal expansion is reflected in the thermal expansion of the medium-range order. Thus, from the behavior of the relative $G(r)$ peak positions illustrated in Fig. 13, we conclude that low-temperature aging in this alloy occurs predominantly on the short-range order length scale (up to $\sim 5.5 \AA$ ), while the medium-range order remains largely unaffected. Moreover, the low-temperature aging observed here can not be explained in simple terms of free volume, but rather comprises distinct changes in the CSRO though local optimization of atomic pair interactions. These findings are consistent with the emergent idea that low-temperature aging and the slow $\beta$ relaxation can be characterized by short-range atomic rearrangements in loosely packed or weakly bonded regions $[63,64]$.

\section{Role of $\mathrm{Cu}$ and chemical disordering in the relaxation behavior of $\mathrm{Au}_{49} \mathrm{Cu}_{26.9} \mathrm{Si}_{16.3} \mathrm{Ag}_{5.5} \mathrm{Pd}_{2.3}$}

In this section, we will discuss some important chemical aspects associated with the observed low-temperature aging behavior in this particular metallic glass system. Recently, a physical picture has emerged relating the slow $\beta$ relaxation to stringlike motions of atoms, in which the diffusive motion of the smallest constituent atoms has been intimately linked with the apparent activation energy of the slow $\beta$ relaxation [38]. For the case of this $\mathrm{Au}_{49} \mathrm{Cu}_{26.9} \mathrm{Si}_{16.3} \mathrm{Ag}_{5.5} \mathrm{Pd}_{2.3} \mathrm{BMG}$, it is likely that the low-temperature relaxation phenomena observed in the previous sections are aided through the fast diffusion of elements whose cores are highly polarizable, like $\mathrm{Ag}$ and $\mathrm{Cu}$, which seem to be particularly mobile [65]. Furthermore, as a consequence of its small ionic radius, elemental $\mathrm{Cu}$ has a relatively weak interaction with the $\mathrm{Si}$ lattice, making it highly mobile even at room temperature [66], while $\mathrm{Au}$ can be seen as the slowest (given its large size), even if its diffusivity is known to increase by one order of magnitude when $\mathrm{Si}$ is present. Although this comparison is based on diffusivities measured in crystalline metals, one can nevertheless speculate that a similar interaction occurs in glassy metals as well. Indeed, the similarity between the activation energy for $\mathrm{Cu}$ diffusion in amorphous $\mathrm{Si}$ of $1.2 \mathrm{eV}$ [67] and the slow $\beta$-relaxation activation energy $E_{\beta}^{\prime}=$ $0.92 \mathrm{eV}$, determined from Fig. 8, would lend support to this conclusion.

Findings from additional studies also highlight the role played by $\mathrm{Cu}$ in various low-temperature aging and relaxation phenomena related to this BMG system. For example, Eisenbart et al. $[68,69]$ have recently reported that the large amount of $\mathrm{Cu}$ in this particular composition, in combination with the presence of $\mathrm{Si}$, is the main contributor to the fast 
tarnishing kinetics observed at room temperature. Furthermore, Yu et al. [38] investigated the chemical influence on slow $\beta$ relaxations in a number of BMG systems and have shown that the presence of $\mathrm{Cu}$ leads to the formation of a pronounced DMA loss peak in Pd-based BMGs. In another study, however, a recent DMA investigation by Qiao et al. [70] of the $\mathrm{Au}_{65} \mathrm{Cu}_{10.5} \mathrm{Ag}_{7.5} \mathrm{Si}_{17}$ BMG showed no obvious slow $\beta$ relaxation, which is presumably due to the absence of the large amount of $\mathrm{Cu}$ that is present in the BMG under investigation in this paper. In light of these results, it is reasonable to suggest that significant amounts of $\mathrm{Cu}$, in combination with the presence of $\mathrm{Si}$, accelerate low-temperature kinetic phenomena on the atomic scale and greatly contribute to the enhancement of dynamical heterogeneities in the glassy state.

Having discussed the effects of $\mathrm{Cu}$ on the low-temperature relaxation behavior of this BMG, the final part of this section will address the possibility of general chemical disordering during aging. As mentioned previously, the different chemical affinities between the constituent atoms in a BMG alloy can have a pronounced effect on its physical properties. The effects of chemical ordering/disordering on the mechanical properties of crystalline and amorphous alloys have been well documented. For example, in crystalline $\mathrm{Cu}_{3} \mathrm{Au}$ and $\mathrm{Mg}_{3} \mathrm{Cd}$ alloys, both of which exhibit an order-disorder transition, the increase in Young's modulus observed during annealing after quenching from the an initially disordered state is attributed to the growth of ordered domains [71,72]. Indeed, similar behavior is observed in Fig. 2 and it now becomes relevant to examine whether we can identify a distinct chemical ordering/disordering process in these experiments.

A significant limitation of the synchrotron x-ray experiments carried out in these studies is the inability to separate the individual partial structure factors from the total measured $S(Q)$. As such, no exact information can be provided on the distinct atomic rearrangements of each individual species. However, the irreversible narrowing of the FWHM combined with the increase in intensity of the first $S(Q)$ maximum (both $\sim 1 \%$ ) after the first heating run observed in Fig. 9 does indicate a significant reduction in disorder. While it still remains unclear to what extent this reduction reflects the relatively small change in characteristic length scale ( $\sim 0.3 \%)$, the trend observed in the Young's modulus (Fig. 2) during low-temperature annealing supports the idea of rapid chemical disordering followed by much slower reordering processes as suggested by van den Beukel et al. [15]. Furthermore, the structural data shown in Figs. 12 and 13 provide clear evidence of atomic rearrangements occurring primarily on the nearest-neighbor and next-nearest-neighbor length scales during low-temperature annealing and agrees with the established picture that changes in the CSRO only involve local atomic rearrangements on a very small length scale, without the reduction in a significant amount of excess free volume $[3,58,73]$.

\section{v. CONCLUSIONS}

Based on a study of the low-temperature aging behavior and atomic structural rearrangements of a
$\mathrm{Au}_{49} \mathrm{Cu}_{26.9} \mathrm{Si}_{16.3} \mathrm{Ag}_{5.5} \mathrm{Pd}_{2.3} \mathrm{BMG}$, the following conclusions can be made:

(i) There is evidence of a distinct slow $\beta$-relaxation regime in this BMG marked by pronounced changes observed in the Young's modulus during long-time annealing and an excess wing of the DMA loss modulus beginning at $\sim 50{ }^{\circ} \mathrm{C}$ that extends over a wide temperature range up to the glass transition. This was interpreted as the distinct hump belonging to the slow $\beta$ relaxation, superimposed onto the long tail of a broad $\alpha$-relaxation regime.

(ii) MDSC results also showed a broad, nonreversing, and largely irreversible sub- $T_{g}$ endotherm that was associated with the slow $\beta$ relaxation and attributed to loose regions of the glassy structure coming to equilibrium at temperatures still below $T_{g}$. The apparent activation energy for this process was determined to be $0.92 \mathrm{eV}$, which is in very good agreement with an empirical relation for the slow $\beta$-relaxation activation energy.

(iii) Isochronal synchrotron $\mathrm{x}$-ray experiments show distinct atomic rearrangements occurring at the onset of the measured slow $\beta$-relaxation temperature regime that are confined mainly to short-range order length scale while no significant atomic rearrangements occur on the length scale of the medium-range order.

(iv) Comparisons of the measured isothermal evolution of the Young's modulus with isothermal synchrotron $\mathrm{x}$-ray results suggest that significant changes in the CSRO occur during low-temperature aging and are responsible for the modulus changes.

(v) The above findings are all consistent with many current models of a BMG structure consisting of locally mobile regions embedded in a denser, more immobile matrix. The presence of semimetallic $\mathrm{Si}$ in this alloy enhances the mobility of the other constituent elements, $\mathrm{Cu}$ in particular, and plays a role in the rapid relaxation behavior observed in this alloy at low temperatures.

\section{ACKNOWLEDGMENTS}

This research was funded by Project No. $16843 \mathrm{~N}$ of the German Federation of Industrial Research Associations (AiF/IGF) and the Deutsche Forschungsgemeinschaft (German Research Foundation) through Grant No. GA 1721/2-1. Z.E., I.G., and R.B. wish to thank A. Zielonka, U. Klotz, and M. Eisenbart of the Forschungsinstitut für Edelmetalle und Metallchemie (FEM) in Schwäbisch Gmünd for their cooperation and C. Hafner Precious Metal Technology for supplying the precious metals. J.J.K. would like to acknowledge financial support from the Alexander von Humboldt Foundation Fredrick Wilhelm Bessel Research Award. The authors are grateful to J. Bednarčik for his help with setting up the X-ray experiments. At the UdS the authors thank L. Schmitt for helping prepare the samples, R. Krämer for help with the DMA experiments, and J. E. Huacuja-Sánchez for help with the MDSC experiments. Z.E. also thanks F. Yang of the DLR Institute for Materials Physics in Space for many fruitful discussions and the German Academic Exchange Service (DAAD) for their financial support. 
[1] M. E. Launey, J. J. Kruzic, C. Li, and R. Busch, Appl. Phys. Lett. 91, 051913 (2007).

[2] V. H. Hammond, M. D. Houtz, and J. M. O’Reilly, J. Non-Cryst. Solids 325, 179 (2003).

[3] C. Nagel, K. Rätzke, E. Schmidtke, F. Faupel, and W. Ulfert, Phys. Rev. B 60, 9212 (1999).

[4] Z. Evenson and R. Busch, Acta Mater. 59, 4404 (2011).

[5] J. J. Lewandowski, W. H. Wang, and A. L. Greer, Philos. Mag. Lett. 85, 77 (2005).

[6] R. Gerling, F. P. Schimansky, and R. Wagner, Acta Metall. 36, 575 (1988).

[7] P. Murali and U. Ramamurty, Acta Mater. 53, 1467 (2005).

[8] M. E. Launey, R. Busch, and J. J. Kruzic, Acta Mater. 56, 500 (2008).

[9] M. E. Launey, R. Busch, and J. J. Kruzic, Scr. Mater. 54, 483 (2006).

[10] B. M. Darinskii and Y. E. Kalinin, Glass Phys. Chem. 26, 349 (2000).

[11] A. L. Greer and J. A. Leake, J. Non-Cryst. Solids 33, 291 (1979).

[12] M. G. Scott, Scr. Metall. 15, 1073 (1981).

[13] B. M. Darinskii, Y.E. Kalinin, Y. D. Minakov, and V. V. Smirnov, Glass Phys. Chem. 22, 358 (1996).

[14] A. L. Mulder, S. van der Zwaag, and A. van den Beukel, J. Non-Cryst. Solids 61-62, 979 (1984).

[15] A. van den Beukel, S. van der Zwaag, and A. L. Mulder, Acta Metall. 32, 1895 (1984).

[16] G. P. Johari and M. Goldstein, J. Chem. Phys. 53, 2372 (1970).

[17] W. H. Wang, J. Appl. Phys. 110, 053521 (2011).

[18] H. B. Yu, W. H. Wang, H. Y. Bai, Y. Wu, and M. W. Chen, Phys. Rev. B 81, 220201 (2010).

[19] Z. Wang, H. B. Yu, P. Wen, H. Y. Bai, and W. H. Wang, J. Phys.: Condens. Matter 23, 142202 (2011).

[20] Z. F. Zhao, P. Wen, C. H. Shek, and W. H. Wang, Phys. Rev. B 75, 174201 (2007).

[21] K. Ngai, J. Non-Cryst. Solids 352, 404 (2006).

[22] P. Rösner, K. Samwer, and P. Lunkenheimer, Europhys. Lett. 68 (2004).

[23] S. T. Liu, Z. Wang, H. L. Peng, H. B. Yu, and W. H. Wang, Scr. Mater. 67, 9 (2012).

[24] D. D. Liang, X. D. Wang, Y. Ma, K. Ge, Q. P. Cao, and J. Z. Jiang, J. Alloys Compd. 577, 257 (2013).

[25] Y. H. Liu, G. Wang, R. J. Wang, D. Q. Zhao, M. X. Pan, and W. H. Wang, Science 315, 1385 (2007)

[26] J. C. Qiao and J. M. Pelletier, J. Appl. Phys. 112, 083528 (2012).

[27] J. Schroers, B. Lohwongwatana, W. L. Johnson, and A. Peker, Appl. Phys. Lett. 87, 061912 (2005).

[28] ASTM E1876 (ASTM International, West Conshohocken, PA, 2009).

[29] A. P. Hammersley, ESRF Internal Report No., ESRF97HA02T, 1997.

[30] P. Juhás, T. Davis, C. L. Farrow, and S. J. L. Billinge, J. Appl. Crystallogr. 46, 560 (2013).

[31] Z. Jiang, C. T. Imrie, and J. M. Hutchinson, Thermochim. Acta 387, 75 (2002).

[32] T. E. Faber and J. M. Ziman, Philos. Mag. 11, 153 (1965).

[33] A. R. Yavari, A. Le Moulec, A. Inoue, N. Nishiyama, N. Lupu, E. Matsubara, W. J. Botta, G. Vaughan, M. Di Michiel, and A. Kvick, Acta Mater. 53, 1611 (2005).

[34] T. C. Hufnagel, R. T. Ott, and J. Almer, Phys. Rev. B 73, 064204 (2006).
[35] S. Wei, F. Yang, J. Bednarcik, I. Kaban, O. Shuleshova, A. Meyer, and A. Busch, Nat. Commun. 4, 2083 (2013).

[36] Smithells Metal Reference Book, 8th ed., edited by W. F. Gale and T. C. Totemeier (Elsevier, Oxford, 2004).

[37] M. Matsuura, W. Zhang, S. Yamaura, T. Fujita, K. Ohara, S. Kohara, and J. Mizuno, Mater. Trans. 54, 1351 (2013).

[38] H. B. Yu, K. Samwer, W. H. Wang, and H. Y. Bai, Nat. Commun. 4, 2204 (2013).

[39] A. Takeuchi and A. Inoue, Mater. Trans. 46, 2817 (2005).

[40] G. P. Johari, in Molecular Dynamics and Relaxation Phenomena in Glasses, edited by T. Dorfmüller and G. Williams, Lecture Notes in Physics, Vol. 277 (Springer, Berlin, Heidelberg, 1987), pp. 90-112.

[41] J. C. Ye, J. Lu, C. T. Liu, Q. Wang, and Y. Yang, Nat. Mater. 9, 619 (2010).

[42] P. Chen, P. Boolchand, and D. G. Georgiev, J. Phys.: Condens. Matter 22, 065104 (2010).

[43] A. R. Berens and I. M. Hodge, Macromolecules 15, 756 (1982).

[44] H. S. Chen, J. Non-Cryst. Solids 46, 289 (1981).

[45] H. Fujimori, M. Mizukami, and M. Oguni, J. Non-Cryst. Solids 204, 38 (1996).

[46] K. Kishimoto, H. Suga, and S. Seki, Bull. Chem. Soc. Jpn. 46, 3020 (1973).

[47] H. Fujimori and M. Oguni, Solid State Commun. 94, 157 (1995).

[48] P. T. Vianco and J. C. M. Li, J. Non-Cryst. Solids 107, 225 (1989).

[49] H. S. Chen and E. Coleman, Appl. Phys. Lett. 28, 245 (1976).

[50] E. Pineda, P. Bruna, B. Ruta, M. Gonzalez-Silveira, and D. Crespo, Acta Mater. 61, 3002 (2013).

[51] H. S. Chen, Rep. Prog. Phys. 43, 353 (1980).

[52] H. B. Yu, W. H. Wang, and K. Samwer, Mater. Today 16, 183 (2013).

[53] E. S. Park, J. H. Na, and D. H. Kim, J. Appl. Phys. 108, 053515 (2010).

[54] J.-C. Lee, Intermetallics 44, 116 (2014).

[55] J. Bednarcik, S. Michalik, M. Sikorski, C. Curfs, X. D. Wang, J. Z. Jiang, and H. Franz, J. Phys.: Condens. Matter 23, 254204 (2011).

[56] B. Ruta, V. M. Giordano, L. Erra, C. Liu, and E. Pineda, J. Alloys Compd., doi:10.1016/j.jallcom.2013.12.162.

[57] N. Mattern, M. Stoica, G. Vaughan, and J. Eckert, Acta Mater. 60, 517 (2012).

[58] C. Nagel, K. Rätzke, E. Schmidtke, J. Wolff, U. Geyer, and F. Faupel, Phys. Rev. B 57, 10224 (1998).

[59] J. Bünz and G. Wilde, J. Appl. Phys. 114, 223503 (2013).

[60] N. Mattern, J. Bednarcik, M. Stoica, and J. Eckert, Intermetallics 32, 51 (2013).

[61] H. B. Lou, X. D. Wang, Q. P. Cao, D. X. Zhang, J. Zhang, T. $\mathrm{Hu}, \mathrm{H}$. K. Mao, and J. Z. Jiang, Proc. Natl. Acad. Sci. USA 110 10068 (2013).

[62] A. Kursumović, M. G. Scott, E. Girt, and R. W. Cahn, Scr. Metall. 14, 1303 (1980).

[63] Y. H. Liu, T. Fujita, D. P. B. Aji, M. Matsuura, and M. W. Chen, Nat. Commun. 5, 3238 (2014).

[64] H. B. Yu, K. Samwer, Y. Wu, and W. H. Wang, Phys. Rev. Lett. 109, 095508 (2012). 
[65] C. A. Angell, K. L. Ngai, G. B. McKenna, P. F. McMillan, and S. W. Martin, J. Appl. Phys. 88, 3113 (2000).

[66] A. A. Istratov and E. R. Weber, J. Electrochem. Soc. 149, G21 (2002).

[67] S. Coffa, J. M. Poate, D. C. Jacobson, W. Frank, and W. Gustin, Phys. Rev. B 45, 8355 (1992).

[68] M. Eisenbart, U. E. Klotz, R. Busch, and I. Gallino, J. Alloys Compd., doi:10.1016/j.jallcom.2013.11.167.
[69] M. Eisenbart, U. E. Klotz, R. Busch, and I. Gallino, Corros. Sci., doi:10.1016/j.corsci.2014.04.024.

[70] J. C. Qiao, H. Wang, J. M. Pelletier, and H. Kato, Mater. Sci. Eng. A 600, 32 (2014).

[71] N. W. Lord, J. Chem. Phys. 21, 692 (1953).

[72] K. Tanaka, H. Abe, and H. Maniwa, Nat. Sci. Rep. Ochanomizu Univ. 6, 89 (1955).

[73] B. Porscha and H. Neuhäuser, Scr. Metall. Mater. 32, 931 (1995). 